\title{
PcsR2 Is a LuxR-Type Regulator That Is Upregulated on Wheat Roots and Is Unique to Pseudomonas chlororaphis
}

OPEN ACCESS

Edited by:

Dilantha Fernando,

University of Manitoba, Canada

Reviewed by:

Teresa Rebecca De Kievit, University of Manitoba, Canada

Elodie Vandelle,

University of Verona, Italy

Sujatha Subramoni,

Singapore Centre for Environmental Life Science Engineering (SCELSE),

Singapore

*Correspondence:

Elizabeth A. Pierson eapierson@tamu.edu

Specialty section:

This article was submitted to Microbe and Virus Interactions with

Plants,

a section of the journal

Frontiers in Microbiology

Received: 08 May 2020 Accepted: 09 October 2020

Published: 10 November 2020

Citation:

Pan H, Pierson LS III, and Pierson EA (2020) PCsR2 is

a LuxR-Type Regulator That is Upregulated on Wheat Roots and is

Unique to Pseudomonas chlororaphis.

Front. Microbiol. 11:560124. doi: 10.3389/fmicb.2020.560124

\author{
Huiqiao Pan ${ }^{1,2}$, Leland S. Pierson III ${ }^{3}$ and Elizabeth A. Pierson ${ }^{1,2,3 *}$ \\ ${ }^{1}$ Molecular and Environmental Plant Sciences Program, Texas A\&M University, College Station, TX, United States, \\ ${ }^{2}$ Department of Horticulture Sciences, Texas A\&M University, College Station, TX, United States, ${ }^{3}$ Department of Plant \\ Pathology and Microbiology, Texas A\&M University, College Station, TX, United States
}

LuxR solos are common in plant-associated bacteria and increasingly recognized for playing important roles in plant-microbe interkingdom signaling. Unlike the LuxR-type transcriptional regulators of prototype LuxR/Luxl quorum sensing systems, luxR solos do not have a Luxl-type autoinducer synthase gene associated with them. LuxR solos in plant-pathogenic bacteria are important for virulence and in plant endosymbionts contribute to symbiosis. In the present study, we characterized an atypical LuxR solo, PcsR2, in the biological control species Pseudomonas chlororaphis 30-84 that is highly conserved among sequenced $P$. chlororaphis strains. Unlike most LuxR solos in the plant-associated bacteria characterized to date, pcsR2 is not associated with a proline iminopeptidase gene and the protein has an atypical $\mathrm{N}$-terminal binding domain. We created a pcsR2 deletion mutant and used quantitative RT-PCR to show that the expression of pcsR2 and genes in the operon immediately downstream was upregulated $\sim 10$-fold when the wild type strain was grown on wheat roots compared to planktonic culture. PcsR2 was involved in upregulation. Using a GFP transcriptional reporter, we found that expression of pcsR2 responded specifically to root-derived substrates as compared to leaf-derived substrates but not to endogenous AHLs. Compared to the wild type, the mutant was impaired in the ability to utilize root carbon and nitrogen sources in wheat root macerate and to colonize wheat roots. Phenazine production and most biofilm traits previously shown to be correlated with phenazine production also were diminished in the mutant. Gene expression of several of the proteins in the phenazine regulatory network including PhzR, Pip (phenazine inducing protein) and RpeA/RpeB were reduced in the mutant, and overexpression of these genes in trans restored phenazine production in the mutant to wild-type levels, indicating PcsR2 affects the activity of the these regulatory genes upstream of RpeA/RpeB via an undetermined mechanism. Our results indicate PcsR2 upregulates the expression of the adjacent operon in response to unknown wheat root-derived signals and belongs to a novel subfamily of LuxR-type transcriptional regulators found in sequenced $P$. chlororaphis strains.

Keywords: plant-microbe interactions, interkingdom signaling, LuxR solos, Pseudomonas, phenazine 


\section{INTRODUCTION}

Albeit bacteria are unicellular organisms, they communicate with each other via small diffusible molecules to orchestrate their behaviors in a population density-dependent manner, which facilitates rapid adaptation to the environment (Fuqua et al., 1994; Mukherjee and Bassler, 2019). This cell-cell communication mechanism, known as quorum sensing (QS), enables populations to solve problems that single cells cannot, such as colonization, conjugation, secondary metabolites biosynthesis, biofilm formation, and effective invasion of host organisms (Piper et al., 1993; Fuqua and Winans, 1994; Pierson et al., 1994; Wood et al., 1997; Maddula et al., 2006; Schuster and Greenberg, 2006). In Gram- negative bacteria the diffusible signals are primarily fatty acid-derived whereas in Gram-positive bacteria they are most often derived from small peptides (Waters and Bassler, 2005; Pierson and Pierson, 2007). To date, QS systems utilizing $N$-acyl homoserine lactones (AHLs) are the most common in Gram-negative bacteria, although other types QS signals continue to be discovered (Schaefer et al., 2008; Ahlgren et al., 2011; Brachmann et al., 2013; Brameyer et al., 2015b; Corral-Lugo et al., 2016; Papenfort et al., 2017). The prototypical AHL-based QS system consists of a LuxI-type AHL synthase that produces an AHL signal and a cognate LuxR-type transcriptional regulator that senses the signal and regulates the expression of target genes, and autoinduction is a common feature of quorum sensing. Once the intracellular concentration of the signal exceeds a specific threshold, the signal binds to the LuxR, which in turn binds to a relatively conserved DNA sequence known as the lux box in the promoter region of regulated genes, activating or repressing their expression (Waters and Bassler, 2005). Quorum sensing was first identified in Vibrio fischeri, where LuxR binds the signal and directly activates transcription of the $\operatorname{luxICDABE}$ operon, resulting in an exponential increase in the production of both the signal and bioluminescence (Nealson and Hastings, 1979; Engebrecht et al., 1983; Fuqua and Greenberg, 2002).

Although LuxR transcriptional regulators were first characterized as components of QS systems, it is now recognized a majority of the annotated luxR-type genes do not have a luxI gene in proximity on the bacterial chromosome (Hudaiberdiev et al., 2015). This type of unpaired LuxR is referred to as a LuxR solo (or orphan LuxR) (Fuqua, 2006; Subramoni and Venturi, 2009a). Similar to the LuxRs of two-component QS systems, typical LuxR solo regulators consist of about 250 amino acids and have an autoinducer-binding domain at the N-terminus and a conserved helix-turn-helix (HTH) DNA-binding motif at the C-terminus. As reported previously, LuxR-type proteins exhibit low identities (18-25\%), however, in most QS LuxR-type proteins nine amino acid residues involved in autoinducerbinding and DNA-binding are highly conserved (Gonzalez and Venturi, 2013). Although not universally accepted, the definition of LuxR solo has been expanded to include atypical LuxR solos, e.g., LuxR-type receptors that do not have a classic autoinducer domain (Brameyer et al., 2014; Hudaiberdiev et al., 2015). Atypical LuxRs solos characterized to date retain the HTH DNA-binding at the C-terminus, but have either
Per-ARNT-Sim (PAS) signal-sensing domains, REC (receiver) signal receiver domains, or unidentified domains in place of the autoinducer-binding domain at the N-terminus (Wang et al., 2006; de Bruijn and Raaijmakers, 2009; Brameyer et al., 2014). In the present study, in keeping with the broad definition of LuxR solos, typical and atypical solo LuxR-family homologs will be included in our discussion of LuxR solos regardless of the domains at the N-terminus. LuxR solos are believed to expand the regulatory repertoire of the prototypical QS systems, wherein the LuxR solos or the expression of their encoding genes respond to exogenously produced AHLs, signal-mimics, or as yet unidentified interkingdom signals (Teplitski et al., 2000; Subramoni and Venturi, 2009b; Venturi and Fuqua, 2013; Martínez et al., 2015; Coutinho et al., 2018). It is believed that these widespread LuxR solos may mediate novel interkingdom communication, such as between symbiotic-living bacteria and their hosts (Subramoni and Venturi, 2009a; Gonzalez and Venturi, 2013; Brameyer et al., 2015a).

To date, several LuxR solos in plant-associated bacteria are known to play roles in plant pathogenesis or symbiosis, and some of these LuxR solos or the expression of their encoding genes respond to plant signals. The genes encoding these LuxR solos are usually located on the bacterial chromosome in close proximity to a proline iminopeptidase ( $p i p)$ gene (Gonzalez and Venturi, 2013), which releases an N-terminal residue from a peptide, typically a proline. The promoter region of pip in all these strains contains a 20 bp inverted repeat sequence (lux box). XccR in the plant pathogen Xanthomonas campestris pv. campestris was the first LuxR solo reported to respond to unknown plant signals and both XccR and Pip are important for plant virulence (Zhang et al., 2007). Likewise, in other pathogenic bacteria, LuxR solos such as OryR in Xanthomonas oryzae pv. oryzae (Ferluga et al., 2007; Ferluga and Venturi, 2009; Gonzalez et al., 2013), XagR in Xanthomonas axonopodis pv. glycines (Chatnaparat et al., 2012), XocR in Xanthomonas oryzae pv. oryzicola (Xu et al., 2015), PsaR2 in P. syringae pv. actinidiae (Patel et al., 2014) responds to plant signals and are involved in bacterial pathogenicity, mobility, or host colonization. The genes encoding the LuxR solo NesR in the symbiotic plant-beneficial bacteria Sinorhizobium meliloti (Patankar and González, 2009) and PipR in the cottonwood endophyte Pseudomomas sp. GM79 (Schaefer et al., 2016) are also associated with pip genes and these LuxR solos regulate genes that contribute to symbiosis traits including plant nodulation and plant carbon source utilization, respectively.

In comparison to the aforementioned plant-pathogenic and plant-symbiotic bacteria, the genomes of many well-studied plant growth-promoting rhizobacteria (PGPR) contain numerous genes annotated as encoding solo LuxR-family homologs. For example the genomes of PGPR strains $P$. chlororaphis subsp. aureofaciens $\mathrm{O} 6$ and 30-84, $P$. protegens $\mathrm{Pf}-5$, P. brassicacearum Q8r1-96, P. fluorescens Pf0-1, Q2-87, SBW25, A506, SS101 and P. synxantha BG33R (Loper et al., 2012) contain 12-28 solo luxR-type genes based on gene annotations in the National Center for Biotechnology Information (NCBI) database ${ }^{1}$. Also, in comparison to the aforementioned examples, the context of the

\footnotetext{
${ }^{1}$ https://www.ncbi.nlm.nih.gov/
} 
genes encoding the LuxR solos studied in PGPR thus far present distinctive features. For example, the promoter of the pip gene adjacent to $p s o R$ in $P$. protegens $\mathrm{CHA} 0$ and $P$. protegens $\mathrm{Pf}-5$ lacks a lux-box palindrome (Subramoni et al., 2011) and there is no pip adjacent to lesR in L. enzymogenes (Qian et al., 2014) or viscAR and viscBCR in P. fluorescens SBW25 de Bruijn and Raaijmakers, 2009). LuxR-type regulators ViscAR and ViscBCR have a HTH DNA-binding domain but lack a classic autoinducer domain. All these LuxR solos activate genes important for biological control activity. For example, PsoR activates anti-microbialrelated genes in response to plant signals from wheat and rice but not cucumber. LesR activates the production of heat-stable antifungal factor (HSAF) and ViscAR and ViscBCR regulate viscosin production important for antagonism of oomycete plant pathogens.

Based on these few examples, we hypothesize LuxR solos may enable PGPR to sense and respond to interkingdom signals, facilitating bacterial adaptation to a symbiotic lifestyle and the expression of traits important for plant growthpromoting activities. In the present study, we examined the LuxR-type regulators in the well characterized PGPR strain Pseudomonas chlororaphis subsp. aureofaciens 30-84 (hereafter P. chlororaphis 30-84). This strain was selected as a biological control strain for take-all disease of wheat and was isolated from the roots of wheat grown in a take-all disease suppressive soil (Pierson and Thomashow, 1992; Pierson et al., 2013). Production of phenazines, heterocyclic nitrogen-containing secondary metabolites produced by $P$. chlororaphis 30-84 were shown to be the primary mechanism of disease suppression (Pierson et al., 1994; Pierson and Pierson, 1996). Phenazine production by $P$. chlororaphis $30-84$ is necessary for effective inhibition of the take-all pathogen Gaeumannomyces graminis var. tritici (Pierson and Thomashow, 1992), persistence of P. chlororaphis 30-84 in the wheat rhizosphere (Mazzola et al., 1992), and biofilm formation (Maddula et al., 2006), and wheat seedling drought tolerance (Mahmoudi et al., 2019). Phenazines are produced by a diversity of prokaryotes and have been shown to play roles in Reactive Oxygen Species (ROS) generation, electron shuttling, and iron chelation in other Pseudomonas species (Pierson and Pierson, 2010; Wang et al., 2010, 2011; Recinos et al., 2012; Das et al., 2015). Phenazine biosynthesis is controlled by a complex network of regulatory genes organized in a hierarchical manner (Pierson et al., 1998; Whistler and Pierson, 2003; Pierson and Pierson, 2010; Wang et al., 2012, 2013; Yu et al., 2018). The heart of this network is control by the LuxRtype transcriptional regulator (PhzR), part of the PhzR/PhzI QS system that directly regulates phenazine biosynthesis (Pierson et al., 1994; Wood and Pierson, 1996). A second set of QS genes CsaR/CsaI, indirectly influences phenazine production (Zhang and Pierson, 2001).

In our survey for potentially plant-responsive LuxR solo candidates in the genome of $P$. chlororaphis 30-84, we identified one atypical LuxR solo (PcsR2) based on the observation that pcsR2 expression was highly upregulated when bacteria were grown on wheat roots compared to planktonic culture. We provide evidence that the expression of $p c s R 2$ and the adjacent operon respond to wheat root-derived signals rather than endogenous AHLs, and that PcsR2 is required for this response. We describe bacterial phenotypes modulated by PcsR2. PcsR2 is involved in the expression of bacterial traits that contribute to the utilization of carbon and nitrogen from wheat roots, phenazine biosynthesis, and biofilm production, traits that promote the plant-associated lifestyle and plant growth promoting activity of the bacteria. We discuss the novelty of PcsR2 in relation to other known plant responsive LuxR solos.

\section{MATERIALS AND METHODS}

\section{Bacterial Strains, Plasmids, and Growth Conditions}

Bacterial strains and plasmids used in this study are described in Table 1, and primers are listed in Supplementary Table 1. A spontaneous rifampicin-resistant derivative of $P$. chlororaphis 30-84 was used in all studies and is hereafter referred to as $30-84$ WT. $P$. chlororaphis was grown at $28^{\circ} \mathrm{C}$ in Luria-Bertani (LB) medium (Fisher BioReagents ${ }^{\mathrm{TM}}$, Hampton, $\mathrm{NH}$ ), pigment production medium $\mathrm{D}$ (PPMD), AB minimal media (AB), AB amended with $0.4 \%$ glucose $(A B+G)$, or $A B+G$ amended $2 \%$ casamino acids ( $\mathrm{AB}+\mathrm{CAA})$ media (CAA is from BD Bacto, San Jose, CA), as described previously (Yu et al., 2018). Escherichia coli (E. coli) was grown at $37^{\circ} \mathrm{C}$ in $\mathrm{LB}$ medium. E. coli and $P$. chlororaphis were grown in liquid culture with agitation (200 rotations per minute) or on solid medium (amended with agar at $15 \mathrm{~g} / \mathrm{l})$. Antibiotics were used in the following concentrations for E. coli: kanamycin (Km), gentamicin (Gm), ampicillin (Ap), 5bromo-4-chloro-3-indolyl- $\beta$-D-galactopyranoside (X-gal) at 50, $15,100,40 \mu \mathrm{g} / \mathrm{ml}$, respectively; and for P. chlororaphis: Km, Gm, Ap, rifampicin (Rif), Cycloheximide (Cyclohex) at 50, 50, 100, $100,100 \mu \mathrm{g} / \mathrm{ml}$, respectively.

\section{Phylogenetic Analysis of PcsR2}

LuxR-family homologs within the $P$. chlororaphis 30-84 genome were identified based on annotation (GenBank: CM001559.1) in the National Center for Biotechnology Information (NCBI) database $^{2}$. The amino acid sequences $P$. chlororaphis 30-84 LuxR homologs and other characterized LuxR sequences were retrieved from the Pseudomonas database ${ }^{3}$ or NCBI. Protein domain analysis was performed using the NCBI conserved domain search ${ }^{4}$ and $\mathrm{Pfam}^{5}$. Sequence alignments and amino acid identity comparisons were performed using Clustalomega $^{6}$. Representative LuxRs were displayed graphically using Boxshade $^{7}$. A maximum likelihood (ML) phylogenetic tree was constructed from multiple-sequence alignments of PcsR2 homologs in 48 fully sequenced strains of $P$. chlororaphis with MEGA7 (Kumar et al., 2016) using MUSCLE (MUltiple Sequence Comparison by Log- Expectation). The Jones, Taylor,

\footnotetext{
${ }^{2}$ https://www.ncbi.nlm.nih.gov/

${ }^{3}$ http://www.pseudomonas.com/

${ }^{4}$ https://www.ncbi.nlm.nih.gov/Structure/cdd/wrpsb.cgi

${ }^{5}$ https://pfam.xfam.org/

${ }^{6}$ http://www.ebi.ac.uk/Tools/msa/clustalo/

${ }^{7}$ https://embnet.vital-it.ch/software/BOX_form.html
} 
TABLE 1 | Strains and plasmids used in this study.

\begin{tabular}{|c|c|c|}
\hline Strains and plasmids & Descriptions & References \\
\hline \multicolumn{3}{|l|}{ P. chlororaphis } \\
\hline 30-84WT & $\mathrm{Phz}^{+}, \mathrm{Rif}^{\mathrm{R}}$, wild-type (WT) & Whistler and Pierson, 2003 \\
\hline $30-84 \Delta \mathrm{pcsR} 2$ & $\mathrm{Km}^{\mathrm{R}}$, pcsR2 replaced with $\mathrm{Km}^{\mathrm{R}}$ cassette & This study \\
\hline 30-84 $\Delta$ pcsR2(pGT2PcsR2) & Complemented mutant containing plasmid pGT2PcsR2 & This study \\
\hline 30-84WT(pGT2PcsR2) & WT with plasmid pGT2PcsR2 & This study \\
\hline $30-84 Z N$ & $\mathrm{Phz}^{-}, \mathrm{Rif}^{\mathrm{R}}$, phzB:lacZ genomic fusion & Wood et al., 1997 \\
\hline $30-84 \mathrm{R}$ & $\mathrm{Phz}^{+} \mathrm{Rif}^{\mathrm{R}}$ phzR:Tn5 genomic fusion, $\mathrm{Km}^{\mathrm{R}}$ & Pierson et al., 1994 \\
\hline \multicolumn{3}{|l|}{ E. coli } \\
\hline $\mathrm{DH} 5 \alpha$ & $\begin{array}{l}\mathrm{F}^{-} \text {recA1 endA1 hsdR17 supE44 thi-1 gyrA96 relA1 } \Delta \text { (argF-lacZYA) } 169 \\
\text { Ф80lacZ } \Delta \mathrm{M} 15 \lambda^{-}\end{array}$ & GIBCO-BRL \\
\hline \multicolumn{3}{|l|}{ Plasmid } \\
\hline pGT2PcsR2 & $\begin{array}{l}\text { Promoter tac:pcsR2 fusion in pGT2P created via replacement of lacZ with pcsR2 in } \\
\text { pGT2Ptac:lacZ }\end{array}$ & This study \\
\hline pGT2PpcsR2:gfp & pGT2Ptac:lacZ with promoter of the pcsR2 operon replacing Ptac promoter & This study \\
\hline pGT2P4806:gfp & pGT2Ptac:lacZ with operon 2 promoter replacing Ptac & \\
\hline pGT2Ptac:lacZ & $\begin{array}{l}\text { pGT2 containing a constitutive promoter ptac:lacZ fusion (Ptac promoter drives lacZ } \\
\text { and gfp expression) }\end{array}$ & Yu et al., 2017 \\
\hline pGT2 & pProbe-GT': pVS1 replicon, p15a origin of replication, gfp transcriptional fusion; $\mathrm{Gm}^{\mathrm{R}}$ & Miller et al., 2000 \\
\hline pEX18Ap & $A p^{R}$ & Hoang et al., 1998 \\
\hline pUC4K & $\mathrm{Km}^{\mathrm{R}}, \mathrm{Ap}^{\mathrm{R}}$ & Grindley and Joyce, 1981 \\
\hline pGT2Ptac:phzR & $\begin{array}{l}\text { lacZ in pGT2Ptac:lacZ is replaced with } 0.9 \mathrm{~kb} \text { DNA fragment containing } P \text {. chlororaphis } \\
30-84 \text { phzR }\end{array}$ & Wang et al., 2013 \\
\hline pUCRpeB & $1.2 \mathrm{~kb}$ DNA fragment containing rpeB in pUCP20G & Yu et al., 2017 \\
\hline pUCPip & 784 bp DNA fragment containing pip in pUCP20G & Yu et al., 2017 \\
\hline pUCRpos & $1.4 \mathrm{~kb}$ DNA fragment containing rpos in pUCP20G & Yu et al., 2017 \\
\hline pUCP20G & $\begin{array}{l}G m^{R} \text {, pUCP20 derivative containing constitutive promoter pLac with Smal-flanked } \\
\mathrm{Gm}^{\mathrm{R}} \text { cassette inserted into the unique Scal site within bla }\end{array}$ & Chiang and Burrows, 2003 \\
\hline
\end{tabular}

$A p^{R}, \mathrm{Km}^{R}, \mathrm{Gm}^{R}, \mathrm{Rif}^{R}$, indicate ampicillin, kanamycin, gentamicin, rifampin, respectively.

and Thorton (JTT) model in MEGA 7 and bootstrap analysis with 1,000 replicates were used. Values greater than 50 are indicated at the nodes.

\section{Measuring Gene Expression Levels on Wheat Roots}

The four solo LuxR homologs with the fewest number of substitutions among the nine highly conserved amino acid residues involved in signal-binding and DNA-binding (Gonzalez and Venturi, 2013) were selected for testing (Table 2). Quantitative reverse transcription polymerase chain reaction (qRT-PCR) was used to compare the expression levels of the encoding genes when bacteria were grown in planktonic culture or on wheat roots. For the planktonic culture treatment, bacteria were grown in $\mathrm{AB}+\mathrm{CAA}$ to a standard optical density $\left(\mathrm{OD}_{620}=1.0,28^{\circ} \mathrm{C}\right.$, with agitation $) . \mathrm{A} 1 \mathrm{ml}$ volume of the culture was mixed with $2 \mathrm{ml}$ of Qiagen RNA Protect reagent (Qiagen, Hilden, Germany) to stabilize bacterial RNA. Bacterial cells were collected by centrifugation $(16,000 \times \mathrm{g})$. Whole RNA was extracted, and cDNA was obtained as described below. For the wheat root treatment, the hard red winter wheat cultivar TAM 112 (Reddy et al., 2014; Rudd et al., 2014) was used for all studies. Wheat seeds were surface-disinfested and grown in $\mathrm{CYG}^{\mathrm{TM}}$ (Mega International, Newport, $\mathrm{MN}$ ) germination pouches (in the dark, $28^{\circ} \mathrm{C}$, receiving $10 \mathrm{ml}$ distilled water every 2 days) until the roots were $10-15 \mathrm{~cm}$ in length (610 days). Bacterial inoculum was prepared by growing bacteria in $\mathrm{AB}+\mathrm{CAA}$ to a standard optical density $\left(\mathrm{OD}_{620}=1.0\right.$, at $28^{\circ} \mathrm{C}$, with agitation). Plant roots were immersed in bacterial inoculum for $10 \mathrm{~min}$, and then inoculated plants were transferred to modified germination pouches (roots wrapped in a single moistened sheet of germination paper) and grown for $16 \mathrm{~h}(8 \mathrm{~h}$ light $/ 8 \mathrm{~h}$ dark, $\left.28^{\circ} \mathrm{C}\right)$. The entire root system (6 plants/rep) was rinsed with $5 \mathrm{ml}$ of Qiagen RNA Protect reagent (Qiagen, Hilden, Germany) to stabilize bacterial RNA and collect the bacteria. The cells were collected by centrifugation $(1,200 \times$ g). Total RNA was extracted using a Qiagen RNeasy Mini Kit (Qiagen) according to the manufacturer's recommended protocol. The genomic DNA was removed using on-column DNase-I digestion (Qiagen) for $15 \mathrm{~min}$. RNA concentration and purity were determined using a GE NanoVue spectrophotometer (GE Healthcare, Pittsburgh, PA). Total RNA (1 $\mu \mathrm{g})$ was reverse transcribed using random primers (Promega, Madison, WI) and AMV Reverse Transcriptase (Promega, Madison, WI) according to the manufacturer's protocol.

A second experiment compared the expression levels of the pcsR2 and two genes in the operon immediately downstream of pcsR2 (Pchl3084_4801, Pchl3084_4803) in 30-84WT, 30$84 \Delta \mathrm{pcsR} 2$, and $30-84 \Delta \mathrm{pcsR} 2$ (pGT2PcsR2) when bacteria were 
TABLE 2 | Representative LuXR regulators and LuXR-family regulators annotated by NCBI in the genome of Pseudomonas chlororaphis 30-84 and their protein characteristics.

\begin{tabular}{|c|c|c|c|c|c|c|c|c|c|c|c|c|c|c|c|}
\hline & \multirow[t]{2}{*}{ Protein or Locus tag } & \multirow[t]{2}{*}{ Organism } & \multirow[t]{2}{*}{ Type } & \multirow[t]{2}{*}{ Protein (aa) } & \multirow[t]{2}{*}{$\mathrm{N}$-terminal domain } & \multirow[t]{2}{*}{ C-terminal } & \multicolumn{6}{|c|}{ Signal-binding domain } & \multicolumn{3}{|c|}{ HTH-domain } \\
\hline & & & & & & & 57 & 61 & 70 & 71 & 85 & 113 & 178 & 182 & 188 \\
\hline & TraR & Agrobacterium tumefaciens & QS & 234 & Autobind-bind & $\mathrm{HTH}$ & W & Y & $\mathrm{D}$ & $P$ & W & G & $E$ & L & G \\
\hline & LuxR & Vibrio fischeri & QS & 250 & Autobind-bind & HTH & W & $\mathrm{Y}$ & D & $\mathrm{P}$ & W & G & $\mathrm{E}$ & L & $\mathrm{G}$ \\
\hline & SdiA & Escherichi coli & QS & 240 & Autobind-bind & $\mathrm{HTH}$ & W & Y & $\mathrm{D}$ & $P$ & W & G & $E$ & L & G \\
\hline & LasR & Pseudomonas aeruginosa & QS & 239 & Autobind-bind & $\mathrm{HTH}$ & W & Y & $\mathrm{D}$ & $P$ & W & G & $E$ & L & G \\
\hline & RhIR & Pseudomonas aeruginosa & QS & 241 & Autobind-bind & $\mathrm{HTH}$ & W & Y & $\mathrm{D}$ & $P$ & W & G & $E$ & L & G \\
\hline & $X_{c c R}$ & Xanthomonas campestris & Solo & 254 & Autobind-bind & HTH & M & W & $\mathrm{D}$ & $P$ & W & G & $E$ & L & $\mathrm{G}$ \\
\hline & OryR & Xanthomonas oryzae & Solo & 254 & Autobind-bind & HTH & M & W & $\mathrm{D}$ & $\mathrm{P}$ & W & G & $E$ & L & G \\
\hline & XagR & Xanthomonas axonopodis & Solo & 254 & Autobind-bind & HTH & M & W & $\mathrm{D}$ & $P$ & W & G & $\mathrm{E}$ & L & $G$ \\
\hline & XocR & Xanthomonas oryzae & Solo & 254 & Autobind-bind & $\mathrm{HTH}$ & M & W & $\mathrm{D}$ & $P$ & W & G & $E$ & L & G \\
\hline & PsaR2 & Pseudomonas syringae & Solo & 254 & Autobind-bind & $\mathrm{HTH}$ & W & W & $\mathrm{D}$ & $P$ & W & G & $E$ & L & G \\
\hline & PipR & Pseudomonas sp. GM79 & Solo & 289 & Autobind-bind & $\mathrm{HTH}$ & W & W & $\mathrm{D}$ & $P$ & W & G & $E$ & L & G \\
\hline & NesR & Sinorhizobium meliloti & Solo & 260 & Autobind-bind & HTH & M & W & $\mathrm{D}$ & $P$ & W & G & $E$ & L & $\mathrm{G}$ \\
\hline & PsoR & Pseudomonas fluorescent & Solo & 252 & Autobind-bind & HTH & W & W & $\mathrm{D}$ & $P$ & W & G & $E$ & L & G \\
\hline & LesR & Lysobacter enzymogenes & Solo & 247 & Autobind-bind & $\mathrm{HTH}$ & W & Y & $\mathrm{D}$ & $P$ & W & G & $E$ & L & G \\
\hline & SmoR & Stenotrophomonas maltophilia & Solo & 234 & Autobind-bind & $\mathrm{HTH}$ & W & G & $\mathrm{C}$ & $P$ & W & G & $E$ & L & G \\
\hline 1 & PhzR & P. chlororaphis 30-84 & QS & 241 & Autobind-bind & HTH & W & Y & $\mathrm{D}$ & $P$ & W & G & $E$ & L & G \\
\hline 2 & CsaR & P. chlororaphis 30-84 & QS & 241 & Autobind-bind & $\mathrm{HTH}$ & W & Y & $\mathrm{D}$ & $P$ & W & G & $E$ & L & G \\
\hline 3 & Pch|3084_0961 & P. chlororaphis 30-84 & Solo & 847 & Unidentified & $\mathrm{HTH}$ & $\mathrm{F}$ & $N$ & $\mathrm{D}$ & A & Y & Y & $E$ & L & G \\
\hline 4 & Pchl3084_1089 & P. chlororaphis $30-84$ & Solo & 220 & REC/CheY/Response_reg & HTH & - & - & - & - & $\mathrm{L}$ & 1 & $E$ & 1 & $\mathrm{G}$ \\
\hline 5 & Pchl3084_1239 & P. chlororaphis $30-84$ & Solo & 216 & REC/CheY/Response_reg & HTH & - & - & $\mathrm{G}$ & $P$ & W & - & Q & L & G \\
\hline 6 & Pchl3084_1430 & P. chlororaphis 30-84 & Solo & 209 & REC/CheY/Response_reg & HTH & $\mathrm{H}$ & A & Q & V & - & G & $E$ & L & G \\
\hline 7 & Pchl3084_2371 & P. chlororaphis 30-84 & Solo & 499 & PAS & HTH & - & $\mathrm{F}$ & V & $\mathrm{P}$ & V & $\mathrm{N}$ & $\mathrm{E}$ & L & $\mathrm{G}$ \\
\hline 8 & Pchl3084_3060 & P. chlororaphis 30-84 & Solo & 224 & REC/CheY/Response_reg & HTH & $\mathrm{L}$ & $\mathrm{L}$ & $\mathrm{R}$ & M & - & G & $\mathrm{E}$ & L & G \\
\hline 9 & Pchl3084_3111 & P. chlororaphis $30-84$ & Solo & 225 & Unidentified & HTH & Y & Y & $\mathrm{D}$ & $P$ & S & G & $E$ & A & G \\
\hline 10 & Pchl3084_3130 & P. chlororaphis 30-84 & Solo & 267 & Unidentified & HTH & C & Y & $E$ & V & $\mathrm{F}$ & G & $E$ & A & G \\
\hline 11 & Pchl3084_3136 & P. chlororaphis 30-84 & Solo & 225 & Unidentified & HTH & Y & Y & $\mathrm{D}$ & $P$ & $S$ & G & $E$ & A & $\mathrm{G}$ \\
\hline 12 & Pchl3084_3179 & P. chlororaphis 30-84 & Solo & 190 & PAS & HTH & W & $N$ & - & - & Y & G & $\mathrm{E}$ & $S$ & G \\
\hline 13 & Pchl3084_3242 & P. chlororaphis 30-84 & Solo & 325 & Unidentified & $\mathrm{HTH}$ & $G$ & $\mathrm{~F}$ & $\mathrm{~N}$ & $N$ & $\mathrm{~L}$ & G & $E$ & $A$ & G \\
\hline 14 & Pchl3084_3368 (PcsR1) & P. chlororaphis $30-84$ & Solo & 239 & Autobind-bind & HTH & W & V & C & $\mathrm{P}$ & W & G & E & $\mathrm{L}$ & G \\
\hline
\end{tabular}

(Continued) 


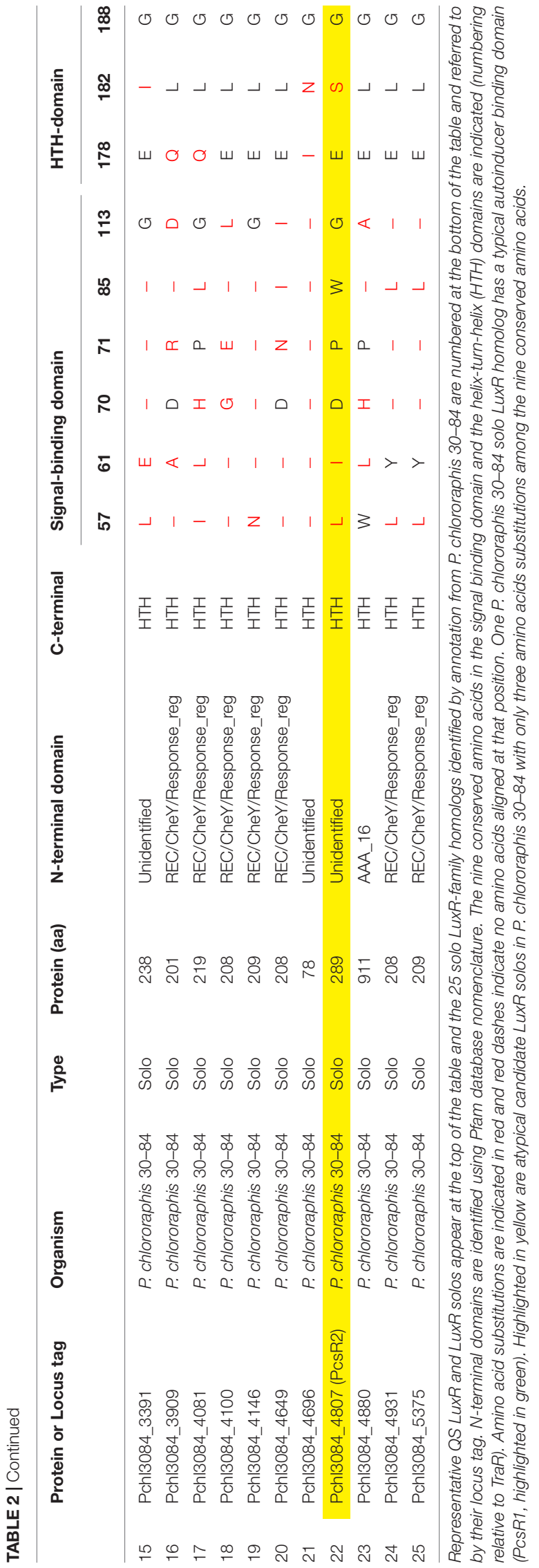

grown in planktonic culture or on wheat roots using qRT-PCR as described above.

SYBR Green reactions were performed using the CFX384 ${ }^{\mathrm{TM}}$ Real-Time System (Bio-Rad, Hercules, CA) in Optical 384Well Reaction 1Plates (Applied Biosystems, Foster City, CA). Quantitative PCR (qPCR) assays were performed to measure the expression levels of the target genes as previously described with minor modifications (Yu et al., 2018). Briefly, synthesized cDNA (5 ng/reaction) or a negative control was used for qPCRs with Fast SYBR Green ${ }^{\circledR}$ PCR Master Mix (Thermo Fisher Scientific, Waltham, MA) and gene-specific primers (250 nM final concentration). qPCR amplification was used to detect the expression of the four $\operatorname{luxR}$ solo genes in the planktonic and wheat root growth treatments. Expression of $r p o D$ was used as the housekeeping control. qPCR amplifications were carried out at $50^{\circ} \mathrm{C}$ for $2 \mathrm{~min}, 95^{\circ} \mathrm{C}$ for $10 \mathrm{~min}$, followed by 40 cycles of $95^{\circ} \mathrm{C}$ for $15 \mathrm{~s}$ and $60^{\circ} \mathrm{C}$ for $1 \mathrm{~min}$, and a final dissociation curve analysis step from 65 to $95^{\circ} \mathrm{C}$. Amplification specificity for each reaction was confirmed by dissociation curve analysis. The relative expression of the target gene was determined based on the mean of cycle threshold $(\mathrm{Ct})$ values and $\Delta \Delta \mathrm{Ct}$ was calculated by normalizing target gene expression to the expression of $r p o D$ as the reference gene. All values are the means of three replicates. The primers for qRT-PCR are listed in Supplementary Table 1.

\section{Generation of pcsR2 Mutant, Complementation, and Overexpression Mutant Cloning Strategy}

A derivative of 30-84WT containing a $p c s R 2$-deletion mutation was generated using strategies and methods described previously (Hmelo et al., 2015) with minor modifications. Briefly, fragments containing the upstream and downstream coding sequences (459 base pair each) flanking $p c s R 2$ were amplified by PCR using the primer pairs 4807KO-UP-F-EcoRI (4807KO-1) and 4807K0UP-R-PstI (4807KO-2), and 4807KO-DN-F-PstI (4807KO-3) and 4807KO-DN-R-HindIII (4807KO-4), respectively. The two amplicons each have $24 \mathrm{nt}$ overlap at $3^{\prime}$ and $5^{\prime}$ end, respectively, due to the overlap of $4807 \mathrm{KO}-2$ and $4807 \mathrm{KO}-3$. Using the primers $4807 \mathrm{KO}-1$ and $4807 \mathrm{KO}-4$ and the products of the previous PCR as a template, overlap PCR was performed. The new product was a DNA fragment that fused the upstream and downstream coding sequence of $p c s R 2$ with a Pst $\mathrm{I}$ site at their junction. This fragment was ligated into the EcoRI and HindIII restriction enzyme sites in the multiple-cloning region of the suicide vector pEX18Ap. The modified plasmid was then transformed into E. coli and screened via blue-white color on LB with ampicillin and Xgal. A Km resistance cassette with its promoter (916 bp) was amplified from pUC4K using primer pairs KmPstI-F and KmPstI-R. Following PstI digestion, the resistance cartridge was inserted into the PstI site of the modified pEX18Ap construct via T4 ligation. The final construct was conjugated into 30-84WT, and positive transformants were selected on LB (amended with $\mathrm{Km}$ and Rif). A double-crossover mutant (30-84 $\Delta$ pcsR2) was obtained by counter-selection with LB amended with $\mathrm{Km}$ and $6 \%$ sucrose and checked by PCR primers 4807KO-UP-UP-F(4807Check1), 4807-DN-DN-R(4807Check2), 
KmPstI-F, 4807qPCR-R PCR was performed using FideliTaq ${ }^{\text {TM }}$ DNA Polymerase (Affymetrix, Santa Clara, CA) or GoTaq ${ }^{\circledR}$ Green Master Mix (Promega, Madison, WI) according to manufacturer instructions. Vector constructions were verified via Sanger sequencing using an ABI 3130xl Genetic Analyzer (Laboratory for Genome Technology, Texas A\&M University). E. coli transformation and $P$. chlororaphis conjugation were performed as described previously (Pierson and Thomashow, 1992; Wang et al., 2012).

\section{Strategy for Complementation and Overexpression}

For complementation of $30-84 \Delta$ pcsR 2 , a plasmid constitutively expressing $p c s R 2$ via the Ptac promoter was created. This was done by replacing the coding sequence of $\operatorname{lac} Z$ with pcsR2 in the expression vector pGT2Ptac:lacZ. The coding sequence of $p c s R 2$ was PCR amplified with the primers 4807-F-BamH1 and 4807-R-HindIII. The resulting fragment was digested with BamHI and HindIII and cloned into the GT2Ptac:lacZ expression vector creating a Ptac:pcsR2 fusion, and the plasmid (pGT2PcsR2) was introduced into E. coli. The sequence was confirmed by Sanger sequencing. The expression vector was transformed to $30-84 \Delta$ pcsR 2 by conjugation to generate $30-84 \Delta \mathrm{pcsR} 2(\mathrm{pGT} 2 \mathrm{PcsR} 2)$, the complemented version of the mutant. A $p c s R 2$ overexpression derivative also was obtained by conjugating the plasmid into $30-84 \mathrm{WT}$ to generate 30-84WT(pGT2PcsR2). For all comparisons utilizing the complement strain, $30-84 \mathrm{WT}$ and $30-84 \Delta$ pcsR 2 containing the plasmid with no insert (NI), e.g., 30-84WT(NI) and 30$84 \Delta$ pcsR2(NI) were used. Standard growth curves were obtained for strains grown in $\mathrm{AB}+\mathrm{CAA}$ at $28^{\circ} \mathrm{C}$, with agitation.

\section{Effect of AHLs and Plant Macerate on Gene Expression and Bacterial Growth}

AHLs were extracted from 30 to $84 \mathrm{ZN}$ (lacks phenazine production) in ethyl acetate and quantified as described previously (Whistler and Pierson, 2003). Wheat macerate was extracted as described previously, with minor modification (Schaefer et al., 2016). Briefly, wheat seeds (variety TAM 112) were surface disinfected and grown in growth pouches as described above. After 6-10 days, $2.5 \mathrm{~g}$ of roots or leaves were macerated in the presence of liquid nitrogen and resuspended in $100 \mathrm{ml}$ distilled water, which then was filtered to remove plant tissue.

A reporter of $p c s R 2$ transcription (pGT2PpcsR2:gfp) was constructed by PCR amplification of the promoter sequence of the pcsR2 operon (Pchl3084_4808-4807) using primers 4808prEcoRI-F and 4808pr-BamHI-R. The PCR product was then ligated into the EcoRI and BamHI sites replacing the Ptac promoter within the reporter vector pGT2Ptac:lacZ (thus the promoter drives both $l a c Z$ and $g f p$ expression, Table 1). Similarly, a reporter of operon 2 transcriptional activity (pGT2P4806:gfp) was constructed by PCR amplification of the promoter sequence of operon 2 (Pchl3084_4806-4800) using primers 4806pr-EcoRI$\mathrm{F}$ and $4806 \mathrm{pr}-\mathrm{Bam} \mathrm{HI}-\mathrm{R}$. The reporters then were introduced into $30-84 \mathrm{WT}$ and $30-84 \Delta$ pcsR 2 by conjugation.

The GFP reporter was used to determine whether certain plant extracts activated gene expression as described previously
(Schaefer et al., 2016) with minor modifications. Strains containing reporter plasmid pGT2PpcsR2:gfp were grown overnight in $\mathrm{AB}+\mathrm{G}$ ( $\mathrm{AB}$ minimal media supplemented $0.4 \%$ glucose) at $28^{\circ} \mathrm{C}$ with agitation and cells were sub-cultured 1:10 into fresh $\mathrm{AB}+\mathrm{G}$ supplemented with and without AHLs or different concentrations $(1,10,20 \% \mathrm{v} / \mathrm{v})$ of root macerate (RM) or leaf macerate (LM) in individual wells of a 96-well microtiter. The plates were incubated at $28^{\circ} \mathrm{C}$ with minimal agitation (10 s mixing, 3 times every $3 \mathrm{~h}$ ). GFP intensity (excitation at $485 \mathrm{~nm}$ and emission at $535 \mathrm{~nm}$ ) and cell density $\left(\mathrm{OD}_{620}\right)$ were measured using Tecan Infinite M200 Pro with I-control software (Tecan, Mannedorf, Switzerland) at $12 \mathrm{~h}$. Strains carrying the no-insert plasmid were used as the blank. Data were plotted as relative fluorescence units (RFU) per OD unit. The $\beta$-galactosidase activity of the reporter was also used to verify gene expression levels as described previously (Yu et al., 2018).

To determine whether wheat root macerate could be used as the primary carbon or nitrogen source, four types of modified bacterial media were prepared: $\mathrm{AB}$ without glucose as the carbon source $(\mathrm{AB}-\mathrm{C}), \mathrm{AB}$ without $\mathrm{NH}_{4} \mathrm{Cl}$ and as the nitrogen source of $(\mathrm{AB}-\mathrm{N}), \mathrm{AB}-\mathrm{C}$ media supplemented with $80 \%$ root macerate $(\mathrm{v} / \mathrm{v})$ as the carbon source $(\mathrm{AB}-\mathrm{C}+\mathrm{M})$, and $\mathrm{AB}-\mathrm{N}$ media supplemented with $80 \%$ root macerate $(\mathrm{v} / \mathrm{v})$ as the nitrogen source $(A B-N+M)$. The three strains $30-84 \mathrm{WT}, 30-84 \Delta$ pcsR2, and $30-84 \Delta$ pcsR2 (pGT2PcsR2) were grown separately overnight in $A B+G$ and the cells were collected via centrifugation $(16,000 \times \mathrm{g})$, washed three times, and resuspended in sterile distilled water. The final cell density was standardized to $\mathrm{OD}_{620}=0.8$. The bacterial cultures were inoculated separately at a 1:100 dilution into a 96 well plate. After $24 \mathrm{~h}\left(28^{\circ} \mathrm{C}\right.$, with agitation), cell density $\left(\mathrm{OD}_{620}\right)$ was measured. A minimum of three replicates per experiment were used and experiments were repeated at least twice.

\section{Root Persistence Assay}

Root persistence assays measuring the populations of 30$84 \mathrm{WT}$ or $30-84 \Delta$ pcsR2 on roots were conducted as described previously with minor modification (Mazzola et al., 1992; Dorosky et al., 2018). Soil used for these experiments was a Pullman clay loam collected from the USDA-ARS, Bushland, TX dryland wheat plots at a depth of $1-15 \mathrm{~cm}$. Prior to use, it was necessary to sieve ( $2 \mathrm{~mm}$ mesh) and mix the soil with sand (soil: sand, 2:1, v:v) to facilitate drainage. The soil-sand mix, hereafter referred to as soil, was autoclaved twice $\left(121^{\circ} \mathrm{C}\right.$, 15 PSI, 1, 24 h pause between cycles). For bacterial inoculum, 30$84 \mathrm{WT}$ and $30-84 \Delta \mathrm{pcsR} 2$ were grown $\mathrm{AB}+\mathrm{CAA}$, collected via centrifugation $(16,000 \times \mathrm{g})$, washed, and resuspended in distilled water to a final $\mathrm{OD}_{620}=1.0$. Aliquots of the cell suspension $(2 \mathrm{ml})$ were diluted with distilled water $(18 \mathrm{ml})$ and added to $500 \mathrm{~g}$ of soil and mixed thoroughly. Soil was dispensed into plastic tubes (Ray Leach Cone-tainers, $2.5 \mathrm{~cm}$ diameter $\times 16.5 \mathrm{~cm}$, $10 \mathrm{~g}$ soil/tube). Prior to planting, wheat seeds (TAM112) were surface disinfested and germinated on sterilized germination paper. Two-day-old seedlings were planted into each container and covered with autoclaved vermiculite 4 days after the bacteria were inoculated into the soil. Each treatment had 10 replicate plants and soil without bacterial inoculation was used as the 
control. After 6 weeks of growth ( $8 \mathrm{~h}$ dark/16 h light cycle at $28^{\circ} \mathrm{C}$ ), the entire root system (and loosely adhering soil) was collected and immersed in $10 \mathrm{ml}$ of phosphate-buffered saline (PBS) solution, and bacteria were collected by sonicating and vortexing. Bacterial populations were enumerated via serial dilution plating onto media (amended with Rif and Cyclohex). $\mathrm{CFU}$ was calculated after $48 \mathrm{~h}$ and normalized to root dry weight $\left(48 \mathrm{~h}, 65^{\circ} \mathrm{C}\right)$.

\section{Growth, Phenazine, and Biofilm Quantification}

For growth curves in $\mathrm{AB}+\mathrm{CAA}, \mathrm{LB}, \mathrm{PPMD}$, populations were quantified spectrophotometrically (at $\mathrm{OD}_{620}$ ) using an Opsys MR Microplate Reader (Thermo Fisher Scientific, Waltham, MA) or via serial dilution plating and colony counting $(\mathrm{CFU} / \mathrm{ml})$. Phenazines were extracted as described previously (Wang et al., 2016). Phenazines were quantified by absorbance at $\mathrm{OD}_{367}$ using a Nanovue plus (GE Healthcare Life Sciences, Pittsburgh, PA). The absorbance for each sample was normalized to the total absorbance of $10 \mathrm{ml}$ cultures.

Surface attached biofilms of cultures grown in 96 well plates were quantified using the crystal violet method as described previously (Maddula et al., 2006) and biofilm populations were quantified spectrophotometrically $\left(\mathrm{OD}_{540}\right)$. The concentration of extracellular (eDNA) present in floating biofilms was quantified $(\mu \mathrm{g} / \mathrm{ml})$ using a Qubit dsDNA Assay Kit and Qubit 2.0 Fluorometer (Invitrogen, Carlsbad, CA) according to the manufacturer's instructions, as described previously (Wang et al., 2012). Matrix from floating biofilms of cultures grown in 24-well plates was collected and quantified as previously described with minor modification (Wang et al., 2016). At the time of sampling, the entire culture (including floating biofilm) was transferred to $1.5 \mathrm{ml}$ Eppendorf tubes and biofilm matrix was collected by centrifugation $(16,000 \times \mathrm{g}$ for $5 \mathrm{~min})$. The supernatants were removed, and the mass of cells and hydrated matrix weighed. For DNase treatment, 30 units of water-dissolved DNase I (Qiagen) were added to $24 \mathrm{~h}$ bacterial cultures and then incubated an additional $24 \mathrm{~h}$. The biofilm matrix was quantified as above.

\section{qRT-PCR of Regulators of Phenazine Production}

Expression levels of phzI, phzR, rpeB, pip (phenazine inducing protein, not proline iminopeptidase), and $r p o S$ were measured via qRT-PCR in 30-84WT(NI), 30-84 $\Delta$ pcsR2(NI) and 30$84 \Delta$ pcsR2(pGT2PcsR2). The protocol for extraction of whole RNA and qRT-PCR was as described above. The primers for qRTPCR are listed in Supplementary Table 1. Gene expression levels were expressed as $\Delta \Delta \mathrm{Ct}$, relative to rpoD.

\section{Constitutive Expression of $p h z R, r p e B$, pip, and rpoS in pcsR2 Mutant}

The previously constructed plasmids pGT2PhzR, pUCPip, pUCRpeB, and pUCRpoS with constitutive promoters were introduced into $30-84 \mathrm{WT}$ and $30-84 \Delta$ pcsR2 by either electroporation or triparental conjugation. After $48 \mathrm{~h}$ incubation, phenazine production was quantified as described above.
$30-84 \mathrm{WT}(\mathrm{NI})$ and $30-84 \Delta \mathrm{pcsR} 2(\mathrm{NI})$, with the empty vector (pGT2 or pUCP20) were used as controls. A minimum of three replicates per experiment were used and experiments were repeated at least twice.

\section{Statistical Analysis}

All data presented are mean \pm the standard error from at least two experiments. Multiple comparisons were analyzed using ANOVA and Turkey HSD and significant differences $(P<0.05)$ are indicated by lowercase letters. Two-group comparisons (WT versus mutant) were performed using Student's $t$-test and asterisks indicate significant differences $(P<0.05)$. All data were analyzed using JMP Version 14 Software (SAS Institute In., Cary, NC).

\section{RESULTS}

\section{Identification of a Novel LuxR Solo With Elevated Gene Expression on Roots}

Twenty-five genes are annotated by NCBI as encoding LuxRfamily transcriptional regulators in the $P$. chlororaphis 30-84 genome, including those encoding the two previously described QS LuxRs (PhzR and CsaR). The other twenty-three solo LuxRtype homologs we refer to by their locus tag and are listed in Table 2. Protein domain analysis indicated that one of the solo LuxR homologs (Pchl3084_3368) is a typical LuxR solo, i.e., having an autoinducer-binding domain (PFAM03472) at the N-terminus (hereafter PcsR1, Table 2). The other twentytwo LuxR-type homologs possess a helix-turn-helix (HTH) DNA-binding domain (PF00196) at the C-terminus, typical of LuxR-family regulators. However, they are atypical in that the N-terminal domains lack autoinducer-binding domains and instead have either PAS signal-sensing, REC/CheY signal receiver, AAA ATPase domains or unidentified domains in place of the autoinducer-binding domains (Table 2). Several of the solo LuxR-family homologs have predicted protein lengths that are considerably smaller than or greater than known LuxR solos (Pchl3084_4696, Pchl3084_0961, and Pchl3084_4880). The typical LuxR solo (Pchl3084_3368) has two substitutions among nine highly conserved amino acid residues. Three of the atypical LuxR solos (Pchl3084_4807, Pchl3084_3111, Pchl3084_3136) have three substitutions among the nine and the others have as many as eight. In our survey for potentially plant-responsive LuxR solo candidates, we focused first on the four homologs with the fewest amino acid substitutions among the conserved amino acids involved in the signal-binding and DNA-binding domains (Table 2).

In a comparative analysis, relative gene expression $(\Delta \Delta \mathrm{Ct}$, measured using qRT-PCR standardized to $r p o D$ ) of one of the four solo LuxR homologs (Pchl3084_4807) was highly upregulated when $30-84 \mathrm{WT}$ was grown on wheat roots compared to growth in planktonic culture $(9.5 \pm 1.4$ vs. $1.0 \pm 0.1$, respectively). In contrast, differences in the gene expression of the other three LuxR homologs were not as pronounced (data not shown). Based on gene expression patterns, Pchl3084_4807, hereafter referred to as PcsR2 became the focus of subsequent 
work. The $p c s R 2$ coding sequence is 870 nucleotides in length and thus predicted to encode a LuxR-type regulator somewhat larger than a typical LuxR (e.g., 289 amino acids vs. 250, respectively), but the same size as the LuxR solo PipR in the cottonwood endophyte Pseudomonas sp. GM79 (Schaefer et al., 2016).

\section{PcsR2 Is a Member of a Novel Subfamily of LuxR-Type Transcriptional Regulators Conserved in $P$. chlororaphis}

Analysis of conserved LuxR protein domains of PcsR2 indicated that it possesses a typical HTH DNA-binding domain (PF00196) at the C-terminus, but no AHL-binding domain (PFAM03472) or any other conserved binding domain at the $\mathrm{N}$-terminus. Amino acid sequence alignment of PcsR2 with other representative LuxR transcriptional regulators was used to compare the nine highly conserved amino acids (red asterisk) within the $\mathrm{N}$-terminal signal-binding and C-terminal HTH domains (Figure 1, indicated by blue vs. black lines, respectively and Table 2). PcsR2 has one substitution out of three highly conserved residues in the HTH domain. Despite the lack of an AHL-binding domain, PcsR2 retains four of six highly conserved amino acid residues within the signal binding domain, which are also conserved in known QS LuxRs (such as LuxR and TraR) as well as previously published plant-responsive LuxR solos such as LesR, PipR, PsoR, NesR, XccR, and OryR. The differences between PcsR2 and the other LuxR solos in the substitutions in the conserved amino acid residues within the signal-binding domain suggest that PcsR2 may respond to different signals than those reported previously for plant-responsive LuxR solos.

Analysis of the $p c s R 2$ gene context indicated that different from previously characterized luxR solo genes such as oryR, $x c c R, x o c R$, or $x a g R$ in plant-pathogenic strains and $p i p R$, or $p s o R$ in plant-beneficial strains (Gonzalez and Venturi, 2013), the $p c s R 2$ locus is not associated with a proline iminopeptidase (pip) gene (although there is a gene locus annotated as encoding this protein elsewhere in the genome (Pchl3084_0411), it is not associated with a transcriptional regulator). Instead, $p c s R 2$ is part of a two gene operon with an AMP-binding protein belonging to a family of adenylate-forming enzymes that generate an acylAMP intermediate (Supplementary Figure 1). Members of this family include long chain fatty acid-CoA ligase, acetyl-CoA synthetase, and various other closely related synthetases. Located downstream is an operon containing two genes annotated as being involved in fatty acid desaturation. PcsR2 bears low amino acid identity with other well-characterized QS LuxR proteins such as LuxR (22\%), TraR (15\%) or even PhzR in P. chlororaphis 30$84(18 \%)$ or LuxR solos such as LesR (20\%), PipR (20\%), and PsoR (20\%) in other plant-associated bacteria. By contrast, it bears extremely high amino acid sequence identity (96-100\%, over the entire amino acid sequence) with PcsR2 homologs found in other sequenced strains of $P$. chlororaphis (Supplementary Table 2) and the organization of these LuxRs in operons with an AMP-binding protein is conserved. Interesting based on amino acid sequence similarity, the PcsR2 homologs in the sequenced $P$. chlororaphis strains generally cluster by subspecies (Supplementary Figure 2).
In support of the hypothesis PcsR2 is a LuxR-type transcriptional regulator of adjacent operon 2 and its own operon, we identified putative lux box homologs in the promoter regions of both operons. In operon 2, the putative lux box sequence is centered 73 bp upstream of translation start codon and in operon 1 it is centered $80 \mathrm{bp}$ upstream of the translational start codon (Supplementary Figure 1). Together, these results are consistent with the hypothesis that PcsR2 is a member of a novel subfamily of LuxR-type transcriptional regulators that is found thus far only in P. chlororaphis.

\section{Expression of pcsR2 and the Downstream Operon Are Upregulated on Wheat Roots}

A derivative of 30-84WT containing a pcsR2-deletion mutation (30-84 $\Delta$ pcsR2) and the mutant complemented via constitutive expression (30-84 $\Delta$ pcsR2(pGT2PcsR2)) were used to verify pcsR2 response to plant signals from roots (Table 1). For all comparisons utilizing the complement, 30-84WT and 30$84 \Delta$ pcsR2 containing the plasmid with no insert (NI), e.g., 30$84 \mathrm{WT}(\mathrm{NI})$ and $30-84 \Delta \mathrm{pcsR} 2(\mathrm{NI})$ were used. All strains grew similarly to each other in planktonic culture in $\mathrm{AB}+\mathrm{CAA}$ and reached stationary phase by $24 \mathrm{~h}$ (Figure 2A). The relative gene expression of $p c s R 2$ ( $\Delta \Delta \mathrm{Ct}$, measured using qRTPCR standardized to $r p o D$ ) was highly upregulated when $30-$ $84 \mathrm{WT}$ was grown on wheat roots as compared to within planktonic culture in $\mathrm{AB}+\mathrm{CAA}$. In contrast, there was almost no expression of $p c s R 2$ in the mutant in either condition, indicating the specificity of the primers. The relative gene expression of $p c s R 2$ in $30-84 \Delta$ pcsR2(pGT2PcsR2) was greater than $30-84 \mathrm{WT}$ in both conditions due to the higher copy number and constitutive expression of $p c s R 2$, but the fold difference in gene expression in the two conditions was less (Figure 2B). These results verified that $p c s R 2$ is upregulated when $30-84 \mathrm{WT}$ is grown on wheat roots and that the mutant and complemented strains performed as expected with respect to $p c s R 2$ gene expression. Transcript abundances of two genes in operon 2 (Pchl3084_4801, Pchl3084_4803) also were measured via qRT-PCR when bacteria were grown on wheat roots and planktonically (Figures 2C,D). Relative gene expression of Pchl3084_4801 and Pchl3084_4803 in 30-84WT were $\sim 10$-fold higher when bacteria were grown on wheat roots as compared to in liquid culture, whereas the relative expression of both genes in operon 2 in the pcsR2 mutant was not upregulated on roots, consistent with PcsR2 involvement in the upregulation of operon 2 on wheat roots. In both conditions, expression of Pchl3084_4801 and Pchl3084_4803 in $30-84 \Delta \mathrm{pcsR} 2$ (pGT2PcsR2) was higher than in $30-84 \mathrm{WT}$, consistent with higher copy number of $p c s R 2$, and similar to 30-84WT, relative gene expression of both genes in operon 2 in $30-84 \Delta$ pcsR2(pGT2PcsR2) were $\sim 6-10$-fold higher when bacteria were grown on roots as compared to in liquid culture. These data are also consistent with PcsR2 involvement in the upregulation of operon 2 on wheat roots. The observation that the expression of Pchl3084_4801 and Pchl3084_4803 in the $30-84 \Delta$ pcsR2(pGT2PcsR2) was higher than in $30-84 \mathrm{WT}$ in 


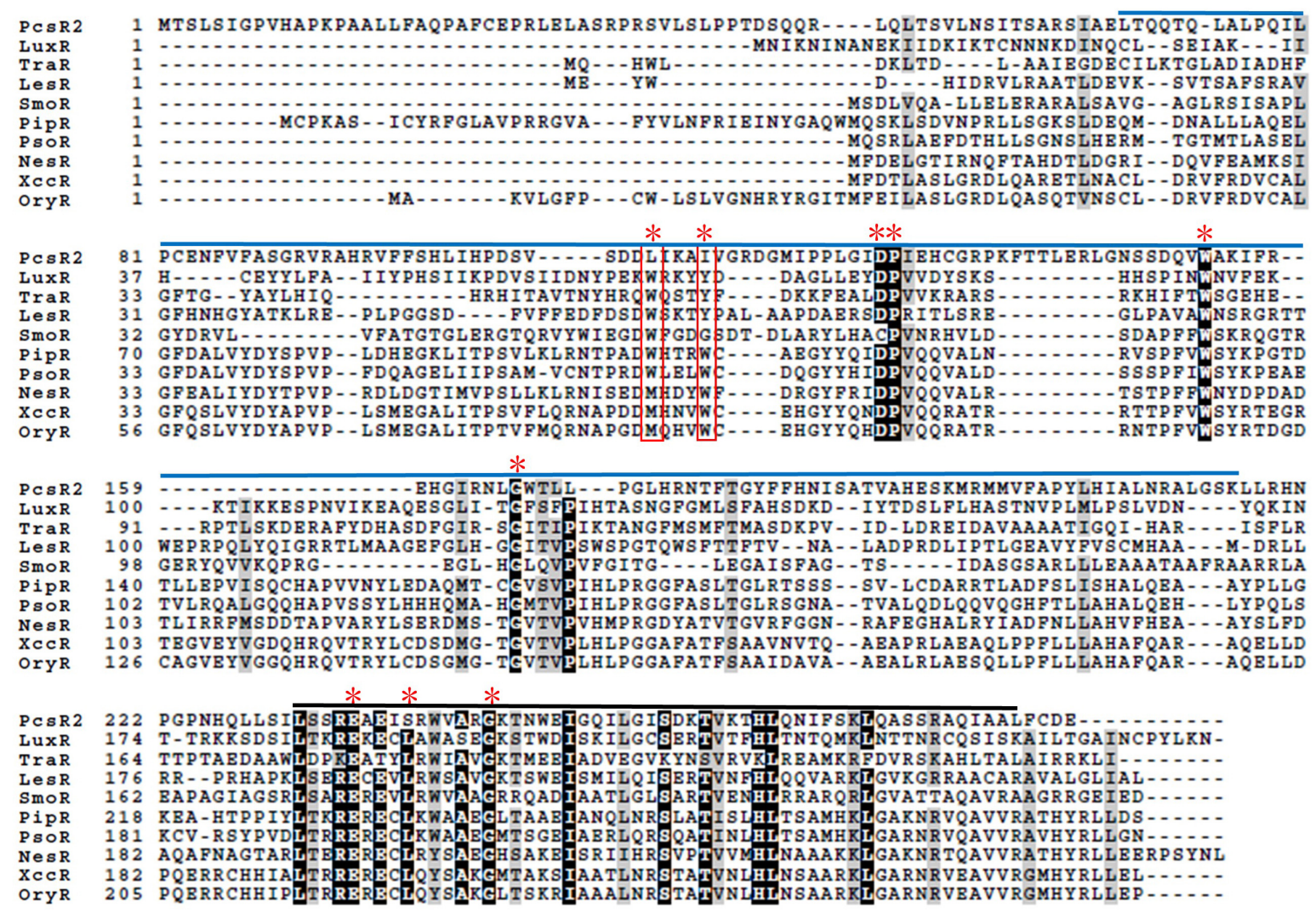

FIGURE 1 | Amino acid sequence alignments of PcsR2 and other representative LuxR-type transcriptional regulators. Sequence alignments and amino acid identity comparisons were performed using Clustal-omega, and Boxshade was used to highlight the degree of amino acid identity (90-100\%). The blue and black lines above the sequences indicate the signal-binding and helix-turn-helix domains of QS LuxRs, respectively. Red asterisks indicate the positions of nine conserved amino acids in QS LuxRs. The two residue positions boxed in red are the most common residues that differ between QS LuxRs (such as LuxR and TraR) and the LuxR solo homologs from plant-associated species (such as PipR, PsoR, NesR, XccR, and OxyR). The PcsR2 sequence also varies in these two positions (L57, I61 instead of $W_{57}, Y_{61}$ in canonical LuxRs; positions numbered as in TraR). Included in this table with PcsR2 are QS LuxR homologs: LuxR in Vibrio fischeri and TraR in Agrobacterium tumefaciens, and LuxR solos: LesR in Lysobacter enzymogenes; SmoR in Stenotrophomonas maltophilia; PipR in Pseudomonas sp. strain GM79; PsoR in P. fluorescens and P. protegens; NesR in Sinorhizobium meliloti; XccR in Xanthomonas campestris pv. campestris; OryR in X. oryzae pv. oryzea.

$\mathrm{AB}+\mathrm{CAA}$, may indicate that the ligand is present at a low level in the absence of wheat roots.

\section{PcsR2 Needed for Root Macerate Utilization and Rhizosphere Colonization}

We were curious whether $p c s R 2$ gene expression was responding specifically to root-derived substrates. The transcriptional reporter pGT2PpcsR2:gfp (containing pcsR2 operon promoter fused to $g f p$ ) transformed into $30-84 \mathrm{WT}$ and $30-84 \Delta \mathrm{pcsR} 2$ was used to quantify $p c s R 2$ expression when strains were grown planktonically in $\mathrm{AB}+\mathrm{G}$ medium supplemented with or without AHLs, root macerate, or leaf macerate. In a preliminary experiment, we measured the expression of $p c s R 2$ over $24 \mathrm{~h}$ and observed that $p c s R 2$ expression plateaued at 12 h (Supplementary Figures 3A,B), so subsequent assays were performed at this time point. Addition of AHLs (extracted from 30 to $84 \mathrm{ZN}$ ) had no effect on the expression of the reporter in either $30-84 \mathrm{WT}$ or $30-84 \Delta \mathrm{pcsR} 2$ (data not shown). Moreover, the expression of pGT2PpcsR2:gfp or pGT2P4806:gfp (containing the operon 2 promoter fused to $g f p$ ) in QS mutant $30-84 \mathrm{R}$ (disrupted in $p h z R$ ) was not significantly different from expression in 30-84WT, indicating neither $p c s R 2$ nor operon 2 is regulated by PhzR (data not shown).

Relative GFP intensity (standardized to cell density) of pGT2PpcsR2:gfp in 30-84WT increased significantly with increasing concentration of root macerate up to $10 \%$, but not with leaf macerate even at the highest concentration (Figures 3A,B). The relative GFP intensity of the reporter in the mutant was unchanged in both conditions, suggesting the mutant may be defective in signal uptake or signal sensing. These findings indicated $p c s R 2$ gene expression responds to unknown signals present in high enough concentration in wheat roots to be detected by the reporter, but not in leaves.

To test whether PcsR2 affects traits involved in utilization of root macerate as a carbon or nitrogen source, the three strains $(30-84 \mathrm{WT}, 30-84 \Delta \mathrm{pcsR} 2, \quad 30-84 \Delta \mathrm{pcsR} 2$ (pGT2PcsR2) were grown separately in modified $\mathrm{AB}$ medium supplemented with root macerate as the sole carbon $(\mathrm{AB}-\mathrm{C}+\mathrm{M})$ or nitrogen $(\mathrm{AB}-\mathrm{N}+\mathrm{M})$ source for $24 \mathrm{~h}$. The modified AB without a carbon 

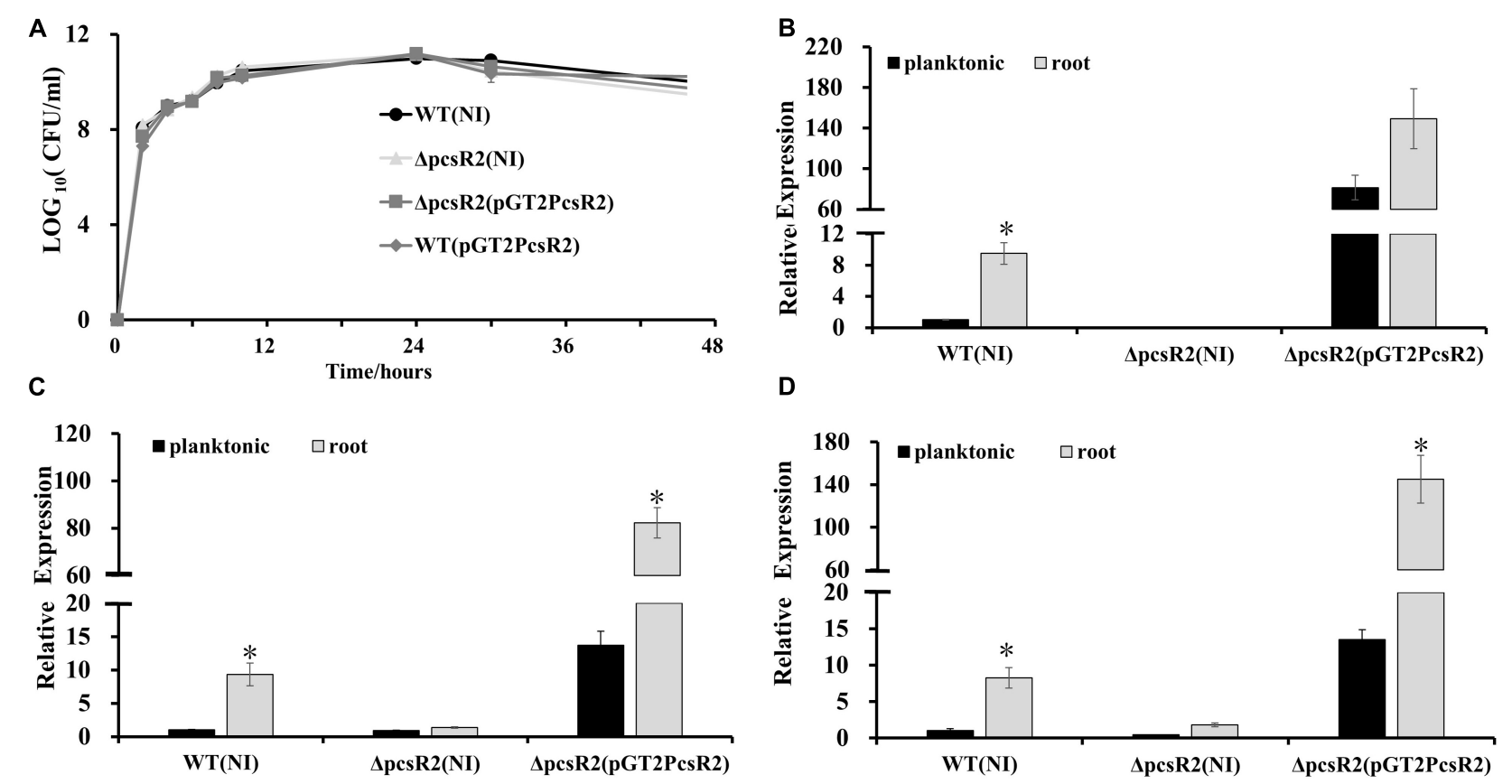

FIGURE 2 | Expression of pcsR2 and the downstream operon were upregulated on wheat roots. (A) Growth curves of strains grown in $A B+C A A$ at $28^{\circ} \mathrm{C}$, for $48 \mathrm{~h}$, with agitation. Populations were enumerated via serial dilution and colony counts (CFU). (B-D) Expression of pcsR2 and two genes in operon 2 (Pchl3084_4801,

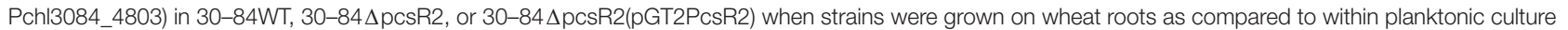
$(\mathrm{AB}+\mathrm{CAA})$ for $16 \mathrm{~h}$. Expression levels were measured via qRT-PCR (where relative gene expression is expressed as $\Delta \Delta \mathrm{Ct}$, with rpoD as internal control) and data are the mean and standard error of nine replicates. Gene expression levels were compared by strain using a Student's $t$-test. Asterisks indicate whether treatments are significantly different $(P<0.05)$.

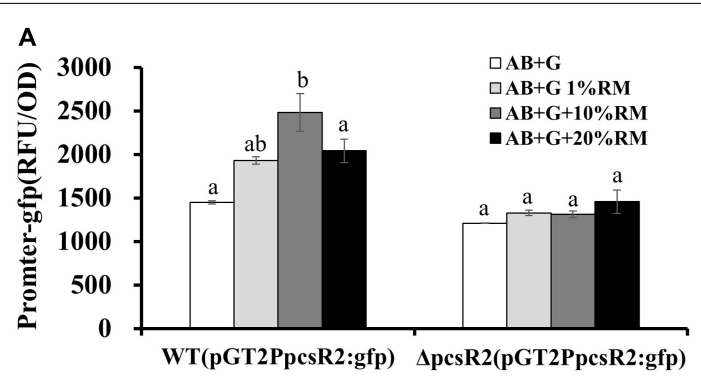

C

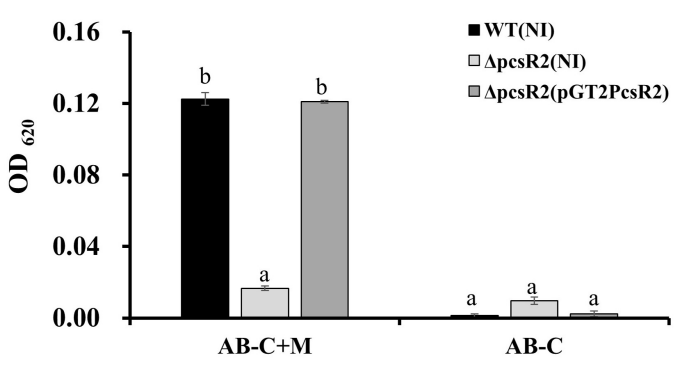

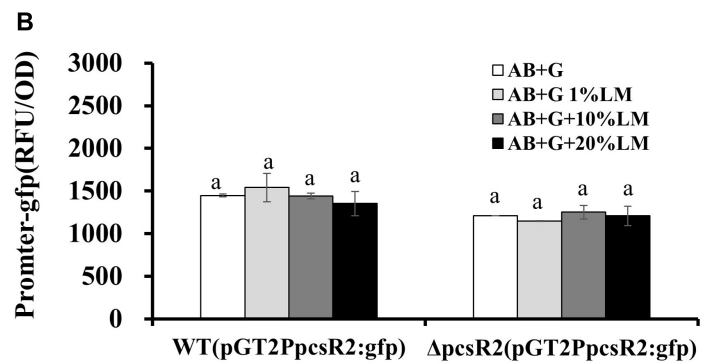

D

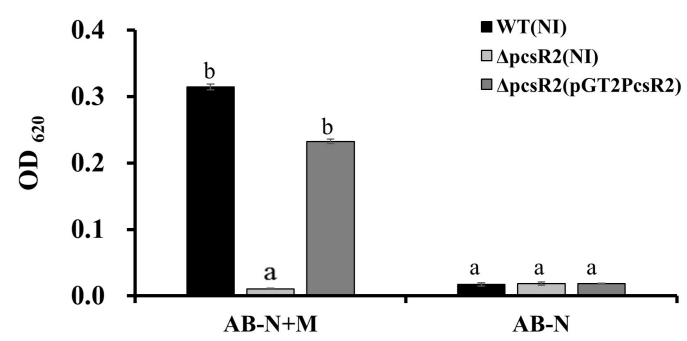

FIGURE 3 | PcsR2 is involved in plant-microbe interactions. (A,B) Expression of the transcriptional pcsR2 GFP reporter (pGT2PpcsR2:gfp) in 30-84WT and $30-84 \Delta$ pcsR2 when incubated in the presence of different concentrations of root or leaf macerate. 30-84WT and 30-84 $\Delta$ pcsR2 carrying the reporter plasmid were incubated in 96 well plates for $12 \mathrm{~h}$ in $\mathrm{AB}$ medium with glucose (AB + G) without or with varying concentrations (1-20\%) of root macerate (RM) (A) or Leaf macerate (LM) (B). GFP fluorescence is expressed as relative fluorescence units (RFU) (fluorescence units standardized to population density). (C,D) Growth 30-84WT, 30-84 $\Delta$ pcsR2, and 30-84 $\Delta$ pcsR2(pGT2PcsR2) in AB medium without a carbon (C) or nitrogen (D) source and with 80\% root macerate (AB-C + M or AB- $\mathrm{N}+\mathrm{M}$ ) or without it (AB-C or AB-N). Population density was measured spectrophotometrically $\left(\mathrm{OD}_{620}\right)$ at $24 \mathrm{~h}$ of growth. $\mathrm{NI}$ means no insert control plasmid. Data are the means and standard errors of three replicates. Letters indicate whether treatments are significantly different $(P<0.05$, ANOVA and Tukey HSD). 
$(A B-C)$ or nitrogen $(A B-N)$ source was used as controls. None of the strains grew well without a supplemental carbon or nitrogen source. $30-84 \mathrm{WT}$ and $\Delta$ pcsR2(pGT2PcsR2) grew significantly better (as measured by $\mathrm{OD}_{620}$ ) than $30-84 \Delta \mathrm{pcsR} 2$ in media supplemented with macerate $(A B-C+M)$ and $(A B-N+M)$. These results suggest PcsR2 effects traits involved in the uptake and/or utilization of carbon and nitrogen sources from wheat root exudates (Figures 3C,D).

To examine whether PcsR2 contributes to rhizosphere colonization and persistence, $30-84 \mathrm{WT}$ and $30-84 \Delta \mathrm{pcsR} 2$ were inoculated separately into soil and after 4 days surface sterilized, pre-germinated wheat seedlings were planted. Bacteria were isolated from roots after 6 weeks and relative CFU (standardized to root dry weight) was calculated. Populations of $30-84 \mathrm{WT}$ on roots were significantly greater $(\sim 10$-fold $)$ than populations of $30-84 \Delta$ pcsR2 (i.e., $\log _{10}(\mathrm{CFU} / \mathrm{g})=7.9 \pm 0.2$ vs. $6.8 \pm 0.1$, respectively).

\section{Loss of PcsR2 Affects Phenazine Production and Biofilm Traits}

An unexpected phenotype of the $30-84 \Delta$ pcsR2 was diminished phenazine production (Figure 4). When grown in $\mathrm{AB}+\mathrm{CAA}$ (Figure 4A), total phenazines produced by $30-84 \mathrm{WT}$ and $30-84 \Delta \mathrm{pcsR} 2(\mathrm{pGT} 2 \mathrm{PcsR} 2)$ were more than twofold greater than the amount of phenazines produced by the mutant (i.e., $\mathrm{OD}_{367}=1.94 \pm 0.20$ and $1.84 \pm 0.20$ vs. $0.68 \pm 0.02$, respectively). However, when grown in media supporting higher phenazine production (e.g., LB or PPMD), the difference between wild type and the mutant in phenazine production was not as pronounced (Figures 4B,C). All strains, 30-84WT, 30-84 $\Delta$ pcsR2, 30$84 \Delta \mathrm{pcsR} 2(\mathrm{pGT} 2 \mathrm{PcsR} 2), \quad 30-84 \mathrm{WT}(\mathrm{pGT} 2 \mathrm{PcsR} 2)$ grew at a similar rate to each other in planktonic culture regardless of media type, indicating this reduction in phenazine production was not a function of population density (Figures $4 \mathrm{D}-\mathrm{F}$ ). These data indicate that a PcsR2 is required for wild type levels of phenazine production, that the defect is more pronounced in certain media, that the complementation of the defect restores phenazine production to wild type levels.

Given the effect of root macerate on $p c s R 2$ gene expression, we were curious whether root macerate would stimulate phenazine production. Phenazine production by $30-84 \mathrm{WT}$ was enhanced when this strain was grown in $A B+G$ media with increasing root macerate supplementation, however phenazine production by $30-84 \Delta$ pcsR 2 was almost unmeasurable and was unchanged by the addition of root macerate (Supplementary Figure 3C). These data are consistent with PcsR2 having an indirect role on phenazine production.

Because production of phenazines was shown previously to be essential for surface attached biofilm formation (Maddula et al., 2006) and to promote extracellular DNA (eDNA) release and extracellular matrix production (Wang et al., 2016), we hypothesized that PcsR2 may contribute to these phenotypes. When grown in $\mathrm{AB}+\mathrm{CAA}$, no differences were measured between 30 and $84 \mathrm{WT}, 30-84 \Delta$ pcsR2, and $30-$ $84 \Delta \mathrm{pcsR} 2$ (pGT2PcsR2) in the number of surface-attached cells after $24 \mathrm{~h}$ growth in static culture or the amount of
eDNA released into floating biofilm cultures. However, by $48 \mathrm{~h}$ the surface-attached populations observed for the 30-84WT and $30-84 \Delta \mathrm{pcsR} 2$ (pGT2PcsR2) increased dramatically and were significantly greater than observed for $30-84 \Delta$ pcsR2 (Figure 5A). eDNA production by $30-84 \mathrm{WT}$ and $30-$ $84 \Delta$ pcsR2(pGT2PcsR2) was also significantly greater than by the mutant (Figure 5B). However, by $48 \mathrm{~h}, 30-84 \Delta$ pcsR 2 produced significantly more extracellular matrix than $30-84 \mathrm{WT}$ or the $30-84 \Delta \mathrm{pcsR} 2(\mathrm{pGT} 2 \mathrm{PcsR} 2)$ and the difference was dramatic after $72 \mathrm{~h}$ in static culture (Figure 5C). As expected, the extracellular matrix of all strains was completely disrupted by the addition of DNase1 (data not shown). Greater matrix production by the mutant was somewhat surprising given that it produced less eDNA, but eDNA was vital to extracellular matrix integrity. Taken together, these results indicate that the reduction in phenazine production associated with the loss of PcsR2 is likely responsible for most, but not all the changes in biofilm characteristics.

\section{Disruption of PcsR2 Reduced the Expression of $p h z R / p h z l$ and Other Phenazine Regulators}

Phenazine biosynthesis is regulated by a hierarchical network of regulatory genes. For example the quorum sensing genes $\mathrm{PhzR} / \mathrm{PhzI}$ are regulated by the phenazine inducing protein Pip (not proline iminopeptidase), which in turn is regulated by the two-component signal transduction system RpeA/RpeB and under nutrient limited conditions the stationary sigma factor RpoS (Whistler and Pierson, 2003; Wang et al., 2012, 2013). In order to examine whether PcsR2 affects the expression of these regulators, we measured their transcript abundance in $30-84 \mathrm{WT}(\mathrm{NI}), \quad 30-84 \Delta \mathrm{pcsR} 2(\mathrm{NI})$, and $30-$ $84 \Delta$ pcsR2(pGT2PcsR2) using qRT-PCR. The relative expression of regulators $p h z I$, $p h z R$, pip, and $r p e B$ (Figure 6A) were significantly lower in 30-84 $\Delta \mathrm{pcsR} 2(\mathrm{NI})$ compared to $30-$ $84 \mathrm{WT}(\mathrm{NI})$ or $30-84 \Delta \mathrm{pcsR} 2$ (pGT2PcsR2). In contrast, the relative expression of rpoS did not differ significantly among the three strains. These results indicate that PcsR2 influences phenazine production via activity of RpeB, Pip, and PhzR/PhzI, but not RpoS.

To confirm the influence of PcsR2 on the RpeB/Pip/PhzR/PhzI regulatory network, extra copies of these regulatory genes under the control of a constitutive promoter were introduced into 3084WT and 30-84 $\Delta$ pcsR2. As expected, in 30-84WT constitutive expression of $p h z R$, pip, or $r p e B$, but not $r p o S$ resulted in a substantially increase in phenazine production. Significantly, in 30-84 p psR2 constitutive expression of $p h z R$, pip, rpeB, but not rpoS restored phenazine production to wild type levels (Figures 6B-E). Consistent with these results, supplementation of growth media with AHLs purified from 30 to $84 \mathrm{ZN}$ (defective in phenazine production) restored phenazine production in $30-$ $84 \Delta$ pcsR2 to wild type levels (data not shown).

The promoter region for operon encoding the two component signal transduction system RpeA/RpeB at the top of the network lacks a lux box. These data suggest that PcsR2 modulates the production of phenazines via an as yet undetermined, indirect 

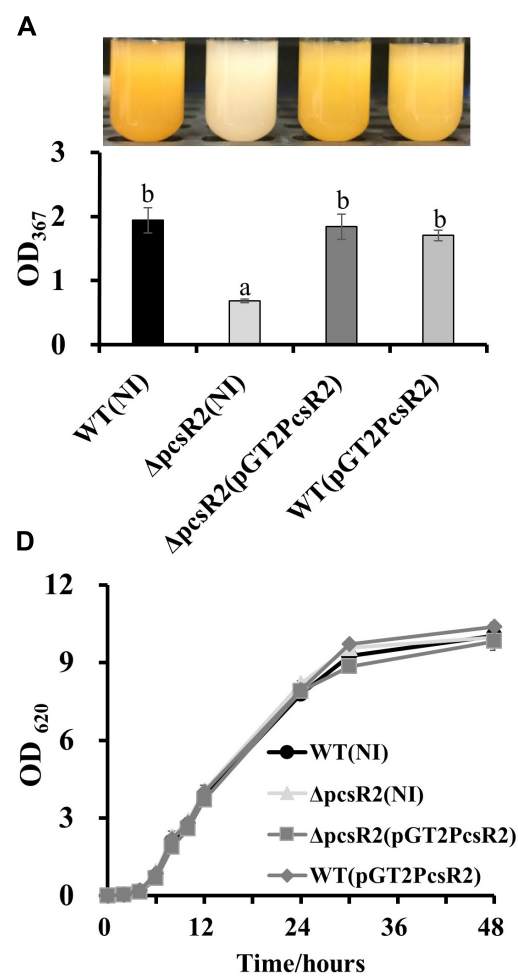

B
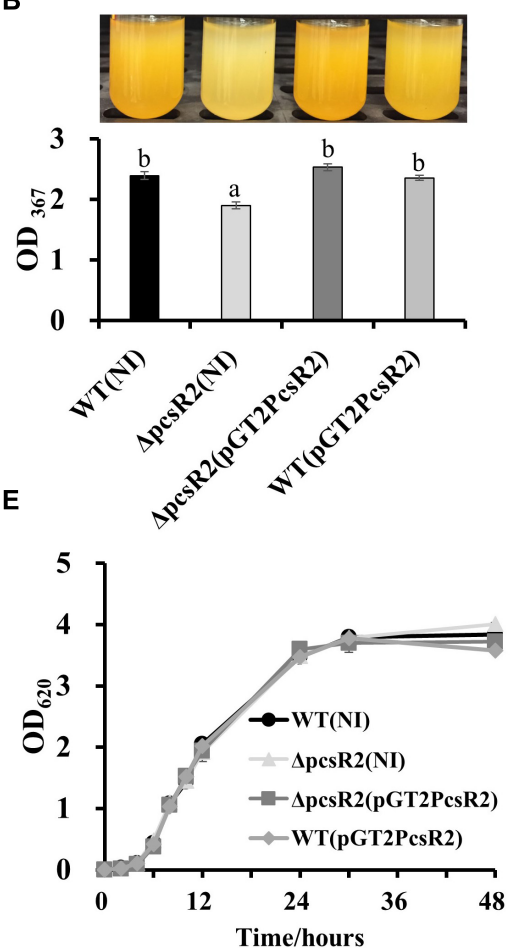

C
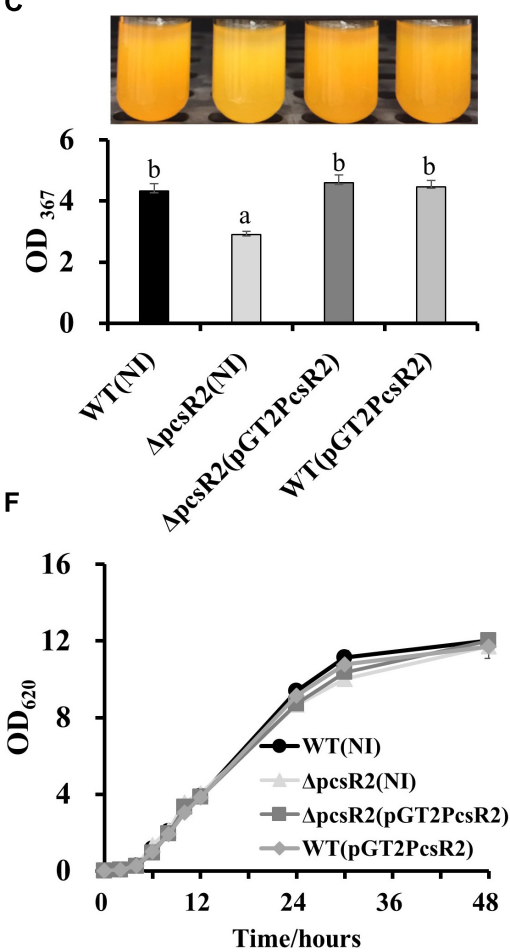

FIGURE 4 | Phenazine production and growth of 30-84WT(NI), 30-84 $\Delta$ pcsR2(NI), and 30-84 4 pcsR2(pGT2PcsR2) and 30-84WT(pGT2PcsR2) in different media. Strains were grown in (A,D) AB + CAA, (B,E) LB, and (C,F) PPMD at $28^{\circ} \mathrm{C}$, for $48 \mathrm{~h}$, with agitation. (A-C) Phenazines were quantified spectrophotometrically $\left(\mathrm{OD}_{367}\right)$ and (D-F) growth curves were calculated spectrophotometrically $\left(\mathrm{OD}_{620}\right)$. NI means no insert control plasmid. Data are the means and standard errors of at least three replicates; some error bars do not exceed the size of symbol. Letters indicate whether treatments are significantly different $(P<0.05$, ANOVA and Tukey HSD).
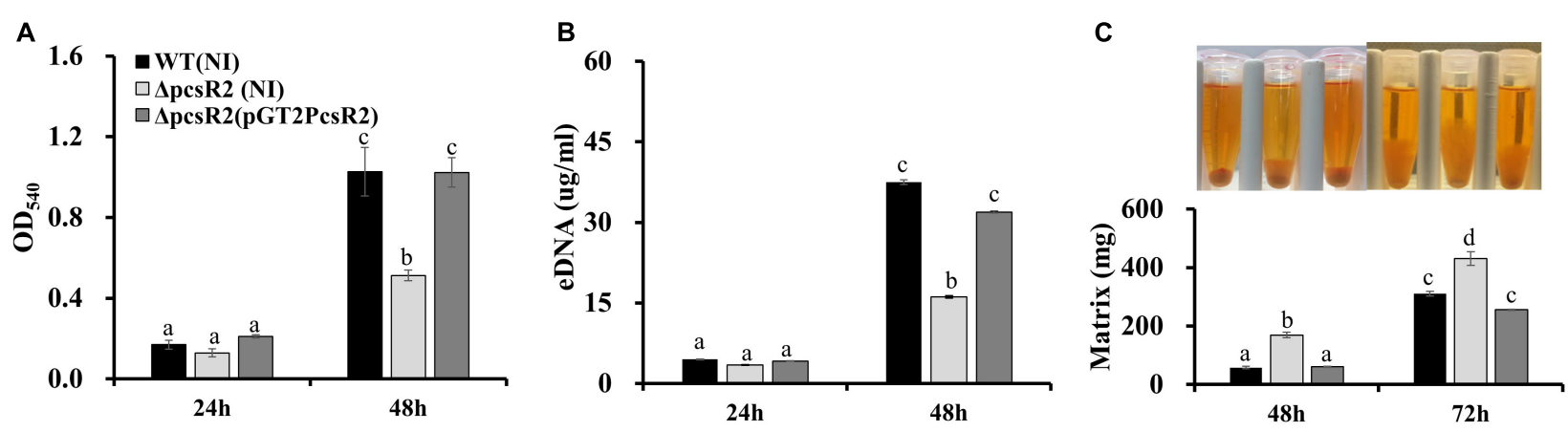

FIGURE 5 | Biofilm traits of 30-84WT(NI), 30-84 $\mathrm{p}$ pcsR2(NI), and 30-84 $\Delta$ pcsR2(pGT2PcsR2). (A) Spectrophotometric quantification of surface-attached biofilms by the crystal violet staining method (at $\mathrm{OD}_{540}$ ) 24 and 48 h. (B) Quantification of extracellular (eDNA) when strains were grown in static culture after 24 and 48 h. (C) Image of biofilm matrix and mass of cells and hydrated matrix when strains grown in static culture measured by weight after 48 and $72 \mathrm{~h}$. All figures use the same labeling for each strain. NI means no insert control plasmid. For all experiments, bacteria were grown in AB + CAA. Data are the means and standard errors of at least three replicates. Letters indicate whether treatments are significantly different $(P<0.05$, ANOVA and Tukey HSD).

effect on the RpeA/RpeB regulatory network that includes Pip and PhzR/PhzI.

\section{DISCUSSION}

Plants and prokaryotes have coexisted and coevolved over millions of years in the rhizosphere. In this specific ecological niche, eukaryotes and prokaryotes communicate efficiently via chemically mediated interkingdom signaling, shaping their evolution and contemporary ecology (Hughes and Sperandio, 2008). Bacterial QS regulation via the production of AHLs, the prototypical QS signal, has been shown to be important for regulating key bacterial traits for bacteria-plant interactions, and the production of AHL mimics by plants highlights the importance of LuxR-based signal-response regulators as 


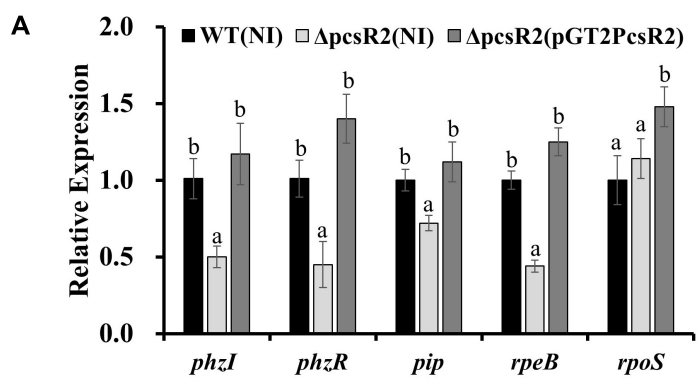

B

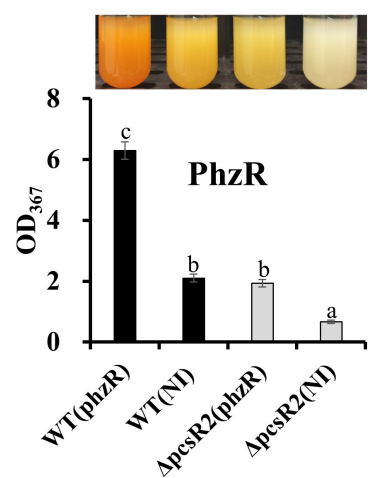

C
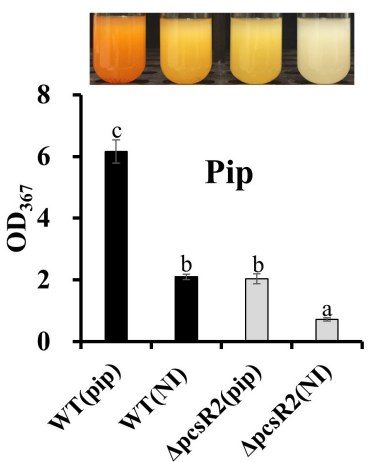
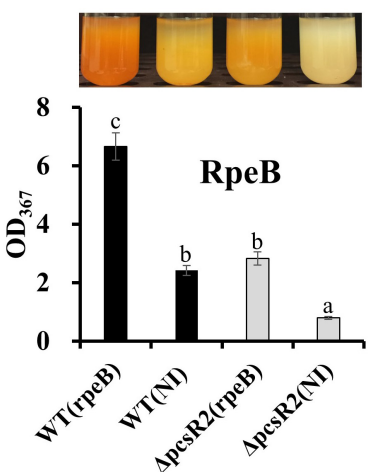

E

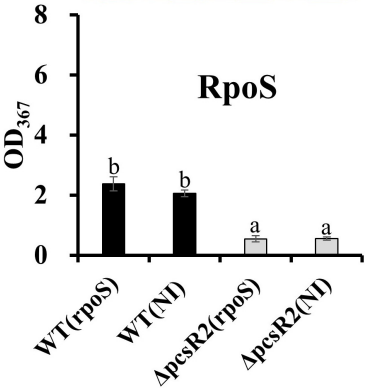

FIGURE 6 | Gene expression of phenazine-regulators and in 30-84WT(NI), 30-84 pcsR2(NI), and 30-84 $\Delta$ pcsR2(pGT2PcsR2) and phenazine production by 30-84WT, and 30-84 $\Delta$ pcsR2 with and without additional copies of some phenazine regulatory proteins in trans. (A) Relative gene expression of some phenazine regulatory genes measured by qRT-qPCR ( $\Delta \Delta \mathrm{Ct}$ method with rpoD as internal control) after $24 \mathrm{~h}$ in $\mathrm{AB}+\mathrm{CAA}$. Relative fold change of these genes is compared to 30-84WT expression levels (which are set to 1). (B-E) Phenazine production of strains with and without additional copies of phzR, pip, rpeB, or rpoS, via expression the following plasmids in trans: pGT2Ptac:phzR, pUCPip, pUCRpeB, pUCRpoS, respectively. NI means no insert control plasmid (pGT2 or pUCP20). Images above graphs are of cultures after $48 \mathrm{~h}$ growth in $\mathrm{AB}+\mathrm{CAA}$ when phenazines were extracted and quantified spectrophotometrically $\left(\mathrm{OD}_{367}\right)$. Data are the means and standard errors of five replicates. Letters indicate whether treatments are significantly different $(P<0.05$, ANOVA and Tukey HSD).

contributing to the recognition of the chemical language involved in interkingdom communication (Loh et al., 2002; Kan et al., 2017). LuxR solos comprise an interesting subgroup of LuxR regulators that may not necessarily respond to an AHL type molecule, and recent observations suggest that LuxR solos are widespread among Gram negative bacteria and may be more common than QS LuxRs in bacterial genomes (Subramoni and Venturi, 2009a; Hudaiberdiev et al., 2015). Thus LuxR solos are good candidates for being mediators of host-PGPR interactions by regulating traits involved in host recognition, host adaptation, or host growth-promoting activities in response to plant signals. In the present study, we focused on LuxR-type regulators in the genome of the well-characterized PGPR strain P. chlororaphis 30-84, which has a diversity of LuxRs, including QS LuxRs and typical and atypical solo LuxR-type regulators. We were particularly interested in plant-responsive gene regulation by any of the LuxR solos.

The twenty-five genes annotated as encoding LuxR-family transcriptional regulators in the $P$. chlororaphis 30-84 genome include the two previously described QS LuxRs (PhzR and CsaR) and twenty-three solo LuxR-type homologs. As is characteristic of LuxR-family proteins, they bear little amino acid sequence identity to one another and are annotated based on the presence of signal-binding and HTH DNA-binding domains. Only one of the LuxR solo homologs is predicted to have an autoinducer binding domain at the N-terminus (PcsR1, Table 2). PcsR1 has two substitutions of the nine highly conserved amino acids in typical QS LuxRs, suggesting it may not bind to AHLs produced by PhzI or CsaI [i.e., N-(3-OH-hexanoyl)- and N-(hexanoyl)HSL or N-(butanoyl)-HSL, respectively, Khan et al., 2007], but may bind to exogenously produced AHLs (i.e., produced by other strains of bacteria) or other types of signals, although this remains to be tested. Interestingly, SmoR in Stenotrophomonas maltophilia, which bears the highest amino acid sequence identity to PcsR1 (53\%) and has amino acid substitutions at the same two positions, is reported to respond to exogenously produced AHL, specifically oxo-C8-homoserine lactone (Martínez et al., 2015). The other twenty-two solo P. chlororaphis 30-84 LuxR-family homologs are atypical in that in place of the autoinducer binding domain, they have either PAS signal-sensing domains, REC/CheY signal receiver domains, or unidentified domains, indicating that they may respond to other types of exogenously-derived signals or stimuli. The N-terminal domains of one half of the atypical solo LuxR-family homologs are annotated as a REC/CheY family of response regulator domains. Response regulators that combine the REC/CheY domain with a DNA binding $\mathrm{HTH}$ domain are common in prokaryotic genomes. Typically, these response regulators are part of two-component signal 
transduction systems that respond to a variety of environmental stimuli or intracellular signals (Galperin, 2006). Interestingly, solo LuxR-family homologs Pchl3084_2371 and Pchl3084_3179 are annotated as having PAS-domains. PAS domains are a family of sensor protein domains involved in signal transduction and are found in all kingdoms of life. They have been shown to bind chemically diverse small-molecule metabolites and to serve as sensors of external stimuli (Henry and Crosson, 2011). For example, the gene downstream of Pchl3084_3179 is annotated as a chitinase. Thus, it may be reasonable to hypothesize that Pchl3084_3179 plays a sensory role in bacteria-fungi interactions by regulating the expression of this gene in direct response to fungal metabolites, although this has yet to be tested.

In the present study, we focused on the LuxR solo PcsR2 because its gene expression is upregulated $\sim 10$-fold on roots. We showed that pcsR2 expression is enhanced specifically in response to root-derived substrates as compared to leaf-derived substrates and does not respond to endogenous AHLs produced by wild type $P$. chlororaphis 30-84. Gene expression of the downstream operon also was highly upregulated on roots in wild type but not in the mutant, consistent with PcsR2 being involved in the regulation of this operon. As was shown via the contrasting behavior of the $p c s R 2$ mutant versus the wild type and complemented mutant, PcsR2s is involved in the metabolism of root-derived carbon and nitrogen, although it is unclear if this is due to PcsR2 effects on metabolite uptake or catabolism. The specificity of $p c s R 2$ transcriptional response is similar to the specificity of LuxR solos in some plant-beneficial Pseudomonas strains. For example, PipR in Pseudomonas sp. GM79, an endophyte of Populus responds specifically to metabolites in leaf but not root macerates. One particular component of leaf macerate, ethanolamine derivatives, was identified as specifically interacting with PipR (Schaefer et al., 2016; Coutinho et al., 2018). For PsoR in the biological control strains P. protegnes CHA0 and $P$. protegens Pf-5, the specificity is for plant signals derived from certain plant species, i.e., plant-produced molecules in rice and wheat but not in cucumber (Subramoni et al., 2011). In the present study, we show that $p c s R 2$ is upregulated in the presence of wheat root macerate but have yet to demonstrate a specific plant-derived signal interaction with PcsR2 on a protein level. However, it is also possible that a plant-derived signal is modified by $P$. chlororaphis 30-84 and that PcsR2 responds to this modified product. The observation that the expression of Pchl3084_4801 and Pchl3084_4803 in 30-84 $\Delta$ pcsR2(pGT2PcsR2) was higher than in $30-84 \mathrm{WT}$ in $\mathrm{AB}+\mathrm{CAA}$, may indicate that the ligand is present at a low level in the absence of root exudates, that there is some induction of operon 2 by PcsR in the absence of ligand, or be an unknown consequence of the higher expression pcsR2 in $30-84 \Delta$ pcsR2(pGT2PcsR2) than $30-84 \mathrm{WT}$ and warrants further study.

Our results suggest that PcsR2 is a member of a novel subfamily of LuxR-type transcriptional regulators found in $P$. chlororaphis that may be involved in the regulation of a conserved fatty acid desaturation locus. PcsR2 bears low amino acid identity with other well-characterized LuxR solos in plant-beneficial species such as LesR, PipR, and PsoR ( $20 \%$ ) but high amino acid sequence identity (96-100\%) with
PcsR2 homologs only found in other sequenced strains of P. chlororaphis (Supplementary Table 2). Additionally, unlike the other plant responsive LuxR solos characterized to date, $p c s R 2$ is not associated with a proline iminopeptidase ( $p i p)$ gene. It is part of a two-gene operon with an AMP-binding protein. Located downstream is a fatty acid desaturase containing operon (Supplementary Figure 1) and this operon is present and topologically organized in the same manner in all other sequenced $P$. chlororaphis strains with PcsR2 homologs (NCBI database, as of this date).

An interesting discovery was the involvement of PcsR2 in phenazine production. We observed that compared to wild type or the complemented mutant, phenazine production by the $p c s R 2$ mutant was significantly reduced even after cultures attained a high cell density and entered into stationary phase. Moreover, we found that phenazine production was enhanced in the wild type when grown in minimal media supplemented with root macerate, however, no such increase in phenazine was observed in the pcsr2 mutant, consistent with and indirect role of PcsR2 in phenazine production. Compared to wild type and the complemented mutant, the formation of surface attached biofilm communities by the pcsR2 mutant was also diminished. We hypothesize this biofilm phenotype is related to the reduced phenazine production by the mutant. This hypothesis is supported by previous reports showing that phenazine production is required for the formation of surface attached biofilm communities (Maddula et al., 2006). Phenazine production also was shown previously to contribute to eDNA release associated with autolysis, resulting in more extensive biofilm matrix production and viscosity (Das and Manefield, 2012; Das et al., 2015; Wang et al., 2016). Somewhat surprisingly, although the wild type and complemented mutant released large quantities of eDNA and produced extensive biofilm matrix, we found that the $p c s R 2$ mutant produced significantly more extracellular matrix, but significantly less eDNA. As expected, the extracellular matrix of the wild type, mutant and complemented mutant were completely disrupted by the addition of DNase1, indicating eDNA is required for matrix integrity, but the mutant must be contributing as yet unidentified component(s) to the matrix.

Our data suggest that PcsR2 affects phenazine production in $P$. chlororaphis 30-84 indirectly via the network of regulatory genes that control phenazine biosynthesis. Data presented in this study indicate that mutation of $p c s R 2$ results in a reduction in the expression of key phenazine regulatory genes $p h z R$, pip (a gene encoding phenazine inducing protein, not proline iminopeptidase), and $r p e B$, and that phenazine production can be restored to wild-type levels by expressing any of these genes in trans in the mutant. These findings are in agreement with previous work that demonstrated phenazine biosysnthesis in $P$. chlororaphis $30-84$ is regulated by the PhzR/PhzI QS system, which in turn is positively regulated by Pip (phenazine inducing protein) and the response regulator RpeB, part of the RpeA/RpeB two component signal transduction system (Wang et al., 2012). According to the model proposed in that study, the RpeA/RpeB two component system may function as a sensor of the metabolic or environmental stress condition of the cell, governing the production of secondary metabolites under stress conditions via 
the control of additional regulatory proteins. In that model, the membrane bound sensor kinase protein RpeA is proposed to control the level of active, phosphorylated RpeB, which in turn promotes the expression of pip and Pip in turn promotes the expression of phzR (Wang et al., 2012). Our data suggest PcsR2 acts upstream of RpeA/RpeB via an as yet undetermined mechanism. Although the function and role of the genes in the downstream operon have yet to be determined, we hypothesize that PcsR2 regulation of fatty acid desaturation may affect membrane fluidity. If so, this may affect the function of proteins bound in the outer membrane, including transport proteins or the receptors of two component systems such as RpeA that are likely to be involved in secondary metabolite production. Indeed, previous work using Pseudomonas aeruginosa has shown that mutations that disrupt the fatty acid profile of phospholipids alter membrane fluidity, resulting in altered production of QS signals, secondary metabolites, and traits associated survival (Baysse et al., 2005). Future work will focus on the function of the PcsR2regulated genes that appear to be unique to $P$. chlororaphis and their roles in $P$. chlororaphis interactions with plants.

\section{DATA AVAILABILITY STATEMENT}

All datasets generated for this study are included in the article/Supplementary Material, further inquiries can be directed to the corresponding author.

\section{AUTHOR CONTRIBUTIONS}

EP and HP designed the whole experiments. HP carried out the experiments, performed the data analysis, and wrote the first draft. LP and EP contributed to the interpretation of results and revisions of the manuscript. EP provided project supervision and major contribution to the final draft. All authors read and approved the submitted version.

\section{REFERENCES}

Ahlgren, N. A., Harwood, C. S., Schaefer, A. L., Giraud, E., and Greenberg, E. P. (2011). Aryl-homoserine lactone quorum sensing in stem-nodulating photosynthetic bradyrhizobia. Proc. Natl. Acad. Sci. U.S.A. 108, 7183-7188. doi: $10.1073 /$ pnas. 1103821108

Baysse, C., Cullinane, M., Dénervaud, V., Burrowes, E., Dow, J. M., Morrissey, J. P., et al. (2005). Modulation of quorum sensing in Pseudomonas aeruginosa through alteration of membrane properties. Microbiology 151, 2529-2542. doi: 10.1099/mic.0.28185-0

Brachmann, A. O., Brameyer, S., Kresovic, D., Hitkova, I., Kopp, Y., Manske, C., et al. (2013). Pyrones as bacterial signaling molecules. Nat. Chem. Biol. 9, 573-578. doi: 10.1038/nchembio. 1295

Brameyer, S., Bode, H. B., and Heermann, R. (2015a). Languages and dialects: bacterial communication beyond homoserine lactones. Trends Microbiol. 23, 521-523. doi: 10.1016/j.tim.2015.07.002

Brameyer, S., Kresovic, D., Bode, H. B., and Heermann, R. (2014). LuxR solos in Photorhabdus species. Front. Cell. Infect. Microbiol. 4:166. doi: 10.3389/fcimb. 2014.00166

Brameyer, S., Kresovic, D., Bode, H. B., and Heermann, R. (2015b). Dialkylresorcinols as bacterial signaling molecules. Proc. Natl. Acad. Sci. U.S.A. 112, 572-577. doi: 10.1073/pnas.1417685112

\section{FUNDING}

This research was supported by funding from the DOEOffice of Energy Efficiency and Renewable Energy-EERE (DEEE0007104), the Dissertation Fellowship from the Office of Graduate and Professional Studies of Texas A\&M University, and assistantship funding from the Department of Horticultural Sciences and the Molecular \& Environmental Plant Sciences Interdisciplinary Program, Texas A\&M University. The open access publishing fees for this article have been covered in part by the Texas A\&M University Open Access to Knowledge Fund (OAKFund), supported by the University Libraries.

\section{ACKNOWLEDGMENTS}

We thank Drs. Dirk B. Hays, Patricia Klein, Dennis Gross, and Michael Kolomiets and current and former members of the Pierson research group: Drs. Julien Levy, Dongping Wang, Panatda Saenkham, Jun Myoung Yu, Robert Dorosky, Peiguo Yuan and Tessa Rose Mahmoudi, Eric-Olivier Tienebo, and Emily Boak for helpful discussions and assistance with various aspects of the research. We thank Dr. Shuyu Liu's for providing wheat seeds, Dr. Hisashi Koiwa for guidance with microscopy and the use of other equipment, Dr. Ry Young from Center for Phage Technology of Texas A\&M University for providing access to the Tecan Infinite M200 Pro for measuring GFP intensity and Dr. Mei Liu for the guidance in the use of the instrument.

\section{SUPPLEMENTARY MATERIAL}

The Supplementary Material for this article can be found online at: https://www.frontiersin.org/articles/10.3389/fmicb. 2020.560124/full\#supplementary-material

Chatnaparat, T., Prathuangwong, S., Ionescu, M., and Lindow, S. E. (2012). XagR, a LuxR homolog, contributes to the virulence of Xanthomonas axonopodis pv. glycines to soybean. Mol. Plant Microbe Interact. 25, 1104-1117. doi: 10.1094/ mpmi-01-12-0008-r

Chiang, P., and Burrows, L. L. (2003). Biofilm formation by hyperpiliated mutants of Pseudomonas aeruginosa. J. Bacteriol. 185, 2374-2378. doi: 10.1128/jb.185.7. 2374-2378.2003

Corral-Lugo, A., Daddaoua, A., Ortega, A., Espinosa-Urgel, M., and Krell, T. (2016). Rosmarinic acid is a homoserine lactone mimic produced by plants that activates a bacterial quorum-sensing regulator. Sci. Signal. 9:ra1. doi: 10.1126/ scisignal.aaa 8271

Coutinho, B. G., Mevers, E., Schaefer, A. L., Pelletier, D. A., Harwood, C. S., Clardy, J., et al. (2018). A plant-responsive bacterial-signaling system senses an ethanolamine derivative. Proc. Natl. Acad. Sci. U.S.A. 115, 9785-9790. doi: 10.1073/pnas.1809611115

Das, T., Kutty, S. K., Tavallaie, R., Ibugo, A. I., Panchompoo, J., Sehar, S., et al. (2015). Phenazine virulence factor binding to extracellular DNA is important for Pseudomonas aeruginosa biofilm formation. Sci. Rep. 5:8398. doi: 10.1038/ srep08398

Das, T., and Manefield, M. (2012). Pyocyanin promotes extracellular DNA release in Pseudomonas aeruginosa. PLoS One 7:e46718. doi: 10.1371/journal.pone. 0046718 
de Bruijn, I., and Raaijmakers, J. M. (2009). Diversity and functional analysis of LuxR-type transcriptional regulators of cyclic lipopeptide biosynthesis in Pseudomonas fluorescens. Appl. Environ. Microbiol. 75, 4753-4761. doi: 10.1128/ AEM.00575-09

Dorosky, R. J., Pierson, L. S., and Pierson, E. A. (2018). Produces multiple R-tailocin particles that broaden the killing spectrum and contribute to persistence in rhizosphere communities. Appl. Environ. Microbiol. 84, e01230-18. doi: 10. 1128/aem.01230-18

Engebrecht, J., Nealson, K., and Silverman, M. (1983). Bacterial bioluminescence: isolation and genetic analysis of functions from Vibrio fischeri. Cell 32, 773-781. doi: 10.1016/0092-8674(83)90063-6

Ferluga, S., Bigirimana, J., Hofte, M., and Venturi, V. (2007). A LuxR homologue of Xanthomonas oryzae pv. oryzae is required for optimal rice virulence. Mol. Plant Pathol. 8, 529-538. doi: 10.1111/j.1364-3703.2007.00415.x

Ferluga, S., and Venturi, V. (2009). OryR Is a LuxR-family protein involved in interkingdom signaling between pathogenic Xanthomonas oryzae pv. oryzae and Rice. J. Bacteriol. 191, 890-897. doi: 10.1128/jb.01507-08

Fuqua, C. (2006). The QscR quorum-sensing regulon of Pseudomonas aeruginosa: an orphan claims its identity. J. Bacteriol. 188, 3169-3171. doi: 10.1128/jb.188. 9.3169-3171.2006

Fuqua, C., and Greenberg, E. P. (2002). Listening in on bacteria: acyl-homoserine lactone signalling. Nat. Rev. Mol. Cell Biol. 3, 685-695. doi: 10.1038/nrm907

Fuqua, W. C., and Winans, S. C. (1994). A LuxR-LuxI type regulatory system activates Agrobacterium Ti plasmid conjugal transfer in the presence of a plant tumor metabolite. J. Bacteriol. 176, 2796-2806. doi: 10.1128/jb.176.10.27962806.1994

Fuqua, W. C., Winans, S. C., and Greenberg, E. P. (1994). Quorum sensing in bacteria: the LuxR-LuxI family of cell density-responsive transcriptional regulators. J. Bacteriol. 176, 269-275. doi: 10.1128/jb.176.2.269-275

Galperin, M. Y. (2006). Structural classification of bacterial response regulators: diversity of output domains and domain combinations. J. Bacteriol. 188, 41694182. doi: $10.1128 / \mathrm{jb}$.01887-05

Gonzalez, J. F., Myers, M. P., and Venturi, V. (2013). The inter-kingdom solo OryR regulator of Xanthomonas oryzae is important for motility. Mol. Plant Pathol. 14, 211-221. doi: 10.1111/j.1364-3703.2012.00843.x

Gonzalez, J. F., and Venturi, V. (2013). A novel widespread interkingdom signaling circuit. Trends Plant Sci. 18, 167-174. doi: 10.1016/j.tplants.2012.09.007

Grindley, N., and Joyce, C. (1981). Analysis of the structure and function of the kanamycin-resistance transposon Tn903. Cold Spring Harb. Symp. Quant. Biol. 45(Pt 1), 125-133. doi: 10.1101/sqb.1981.045.01.021

Henry, J. T., and Crosson, S. (2011). Ligand-binding PAS domains in a genomic, cellular, and structural context. Annu. Rev. Microbiol. 65, 261-286. doi: 10.1146/ annurev-micro-121809-151631

Hmelo, L. R., Borlee, B. R., Almblad, H., Love, M. E., Randall, T. E., Tseng, B. S., et al. (2015). Precision-engineering the Pseudomonas aeruginosa genome with two-step allelic exchange. Nature Protoc. 10:1820. doi: 10.1038/nprot. 2015.115

Hoang, T. T., Karkhoff-Schweizer, R. R., Kutchma, A. J., and Schweizer, H. P. (1998). A broad-host-range Flp-FRT recombination system for site-specific excision of chromosomally-located DNA sequences: application for isolation of unmarked Pseudomonas aeruginosa mutants. Gene 212, 77-86. doi: 10.1016/ S0378-1119(98)00130-9

Hudaiberdiev, S., Choudhary, K. S., Alvarez, R. V., Gelencser, Z., Ligeti, B., Lamba, D., et al. (2015). Census of solo LuxR genes in prokaryotic genomes. Front. Cell. Infect. Microbiol. 5:20. doi: 10.3389/fcimb.2015.00020

Hughes, D. T., and Sperandio, V. (2008). Inter-kingdom signalling: communication between bacteria and their hosts. Nature Rev. Microbiol. 6, 111-120. doi: 10.1038/nrmicro1836

Kan, J. H., Fang, R. X., and Jia, Y. T. (2017). Interkingdom signaling in plantmicrobe interactions. Sci. China Life Sci. 60, 785-796. doi: 10.1007/s11427-0179092-3

Khan, S. R., Herman, J., Krank, J., Serkova, N. J., Churchill, M. E. A., Suga, H., et al. (2007). N-(3-hydroxyhexanoyl)-1-homoserine lactone is the biologically relevant quormone that regulates the phz operon of Pseudomonas chlororaphis strain 30-84. Appl. Environ. Microbiol. 73, 7443-7455. doi: 10.1128/AEM. 01354-07
Kumar, S., Stecher, G., and Tamura, K. (2016). MEGA7: molecular evolutionary genetics analysis version 7.0 for bigger datasets. Mol. Biol. Evol. 33, 1870-1874. doi: 10.1093/molbev/msw054

Loh, J., Pierson, E. A., Pierson, L. S., Stacey, G., and Chatterjee, A. (2002). Quorum sensing in plant-associated bacteria. Curr. Opin. Plant Biol. 5, 285-290. doi: 10.1016/S1369-5266(02)00274-1

Loper, J. E., Hassan, K. A., Mavrodi, D. V., Davis, E. W. II, Lim, C. K., Shaffer, B. T., et al. (2012). Comparative genomics of plant-associated Pseudomonas spp.: insights into diversity and inheritance of traits involved in multitrophic interactions. PLoS Genet. 8:e1002784. doi: 10.1371/journal.pgen.1002784

Maddula, V., Zhang, Z., Pierson, E. A., and Pierson, L. S. (2006). Quorum sensing and phenazines are involved in biofilm formation by Pseudomonas chlororaphis (aureofaciens) strain 30-84. Microbial Ecol. 52, 289-301. doi: 10.1007/s00248006-9064-6

Mahmoudi, T. R., Yu, J. M., Liu, S., Pierson, L. S. III, and Pierson, E. A. (2019). Drought-stress tolerance in wheat seedlings conferred by phenazine-producing rhizobacteria. Front. Microbiol. 10:1590. doi: 10.3389/fmicb.2019.01590

Martínez, P., Huedo, P., Martinez-Servat, S., Planell, R., Ferrer-Navarro, M., Daura, X., et al. (2015). Stenotrophomonas maltophilia responds to exogenous AHL signals through the LuxR solo SmoR (Smlt1839). Front. Cell. Infect. Microbiol. 5:41. doi: 10.3389/fcimb.2015.00041

Mazzola, M., Cook, R. J., Thomashow, L. S., Weller, D. M., and Pierson, L. S. (1992). Contribution of phenazine antibiotic biosynthesis to the ecological competence of fluorescent pseudomonads in soil habitats. Appl. Environ. Microbiol. 58, 2616-2624. doi: 10.1128/AEM.58.8.2616-2624.1992

Miller, W. G., Leveau, J. H. J., and Lindow, S. E. (2000). Improved $g f p$ and inaz broad-host-range promoter-probe vectors. Mol. Plant Microbe Interact. 13, 1243-1250. doi: 10.1094/mpmi.2000.13.11.1243

Mukherjee, S., and Bassler, B. L. (2019). Bacterial quorum sensing in complex and dynamically changing environments. Nat. Rev. Microbiol. 17, 371-382. doi: 10.1038/s41579-019-0186-5

Nealson, K. H., and Hastings, J. W. (1979). Bacterial bioluminescence: its control and ecological significance. Microbiol. Rev. 43, 496-518. doi: 10.1128/mmbr.43. 4.496-518.1979

Papenfort, K., Silpe, J. E., Schramma, K. R., Cong, J.-P., Seyedsayamdost, M. R., and Bassler, B. L. (2017). A Vibrio cholerae autoinducer-receptor pair that controls biofilm formation. Nat. Chem. Biol. 13, 551-557. doi: 10.1038/nchembio.2336

Patankar, A. V., and González, J. E. (2009). An orphan LuxR homolog of Sinorhizobium meliloti affects stress adaptation and competition for nodulation. Appl. Environ. Microbiol. 75, 946-955. doi: 10.1128/aem.01692-08

Patel, H. K., Ferrante, P., Covaceuszach, S., Lamba, D., Scortichini, M., and Venturi, V. (2014). The Kiwifruit emerging pathogen Pseudomonas syringae pv. actinidiae does not produce AHLs but possesses three LuxR solos. PLoS One 9:e87862. doi: 10.1371/journal.pone.0087862

Pierson, E. A., Wang, D., and Pierson, L. S. III (2013). "Roles and regulation of phenazines in the biological control strain Pseudomonas chlororaphis 30-84," in Microbial Phenazines, eds S. Chincholkar and L. Thomashow (Berlin: Springer), 141-162. doi: 10.1007/978-3-642-40573-0_7

Pierson, L. S., Keppenne, V. D., and Wood, D. W. (1994). Phenazine antibiotic biosynthesis in Pseudomonas aureofaciens $30-84$ is regulated by PhzR in response to cell density. J. Bacteriol. 176, 3966-3974. doi: 10.1128/jb.176.13. 3966-3974.1994

Pierson, L. S., and Pierson, E. A. (1996). Phenazine antibiotic production in Pseudomonas aureofaciens: role in rhizosphere ecology and pathogen suppression. FEMS Microbiol. Lett. 136, 101-108. doi: 10.1111/j.1574-6968. 1996.tb08034.x

Pierson, L. S., and Pierson, E. A. (2007). Roles of diffusible signals in communication among plant-associated bacteria. Phytopathology 97, 227-232. doi: 10.1094/phyto-97-2-0227

Pierson, L. S., and Pierson, E. A. (2010). Metabolism and function of phenazines in bacteria: impacts on the behavior of bacteria in the environment and biotechnological processes. Appl. Microbiol. Biotechnol. 86, 1659-1670. doi: 10.1007/s00253-010-2509-3

Pierson, L. S., and Thomashow, L. S. (1992). Cloning and heterologous expression of the phenazine biosynthetic locus from Pseudomonas-aureofaciens 30-84. Mol. Plant Microbe Interact. 5, 330-339. doi: 10.1094/mpmi-5-330 
Pierson, L. S., Wood, D. W., and Pierson, E. A. (1998). Homoserine lactonemediated gene regulation in plant-associated bacteria. Annu. Rev. Phytopathol. 36, 207-225. doi: 10.1146/annurev.phyto.36.1.207

Piper, K. R., von Bodman, S. B., and Farrand, S. K. (1993). Conjugation factor of Agrobacterium tumefaciens regulates Ti plasmid transfer by autoinduction. Nature 362, 448-450. doi: 10.1038/362448a0

Qian, G. L., Xu, F. F., Venturi, V., Du, L. C., and Liu, F. Q. (2014). Roles of a solo LuxR in the biological control agent Lysobacter enzymogenes Strain OH11. Phytopathology 104, 224-231. doi: 10.1094/phyto-07-13-0188-r

Recinos, D. A., Sekedat, M. D., Hernandez, A., Cohen, T. S., Sakhtah, H., Prince, A. S., et al. (2012). Redundant phenazine operons in Pseudomonas aeruginosa exhibit environment-dependent expression and differential roles in pathogenicity. Proc. Natl. Acad. Sci. U.S.A. 109, 19420-19425. doi: 10.1073/ pnas. 1213901109

Reddy, S. K., Liu, S., Rudd, J. C., Xue, Q., Payton, P., Finlayson, S. A., et al. (2014). Physiology and transcriptomics of water-deficit stress responses in wheat cultivars TAM 111 and TAM 112. J. Plant Physiol. 171, 1289-1298. doi: 10.1016/j.jplph.2014.05.005

Rudd, J., Devkota, R., Baker, J., Peterson, G., Lazar, M., Bean, B., et al. (2014). 'TAM 112' wheat, resistant to greenbug and wheat curl mite and adapted to the dryland production system in the southern high plains. J. Plant Registrations 8 , 291. doi: 10.3198/jpr2014.03.0016crc

Schaefer, A. L., Greenberg, E. P., Oliver, C. M., Oda, Y., Huang, J. J., Bittan-Banin, G., et al. (2008). A new class of homoserine lactone quorum-sensing signals. Nature 454, 595-599. doi: 10.1038/nature07088

Schaefer, A. L., Oda, Y., Coutinho, B. G., Pelletier, D. A., Weiburg, J., Venturi, V., et al. (2016). A LuxR homolog in a cottonwood tree endophyte that activates gene expression in response to a plant signal or specific peptides. $m B i o$ 7:e01101-16. doi: 10.1128/mBio.01101-16

Schuster, M., and Greenberg, E. P. (2006). A network of networks: quorum-sensing gene regulation in Pseudomonas aeruginosa. Int. J. Med. Microbiol. 296, 73-81. doi: $10.1016 /$ j.ijmm.2006.01.036

Subramoni, S., Gonzalez, J. F., Johnson, A., Péchy-Tarr, M., Rochat, L., Paulsen, I., et al. (2011). Bacterial subfamily of LuxR regulators that respond to plant compounds. Appl. Environ. Microbiol. 77, 4579-4588. doi: 10.1128/aem.00 183-11

Subramoni, S., and Venturi, V. (2009a). LuxR-family 'solos': bachelor sensors/regulators of signalling molecules. Microbiology 155, 1377-1385. doi: 10.1099/mic.0.026849-0

Subramoni, S., and Venturi, V. (2009b). PpoR is a conserved unpaired LuxR solo of Pseudomonas putida which binds N-acyl homoserine lactones. BMC Microbiol. 9:125. doi: 10.1186/1471-2180-9-125

Teplitski, M., Robinson, J. B., and Bauer, W. D. (2000). Plants secrete substances that mimic bacterial $\mathrm{N}$-acyl homoserine lactone signal activities and affect population density-dependent behaviors in associated bacteria. Mol. Plant Microbe Interact. 13, 637-648. doi: 10.1094/mpmi.2000.13.6.637

Venturi, V., and Fuqua, C. (2013). Chemical signaling between plants and plant pathogenic bacteria. Annu. Rev. Phytopathol. 51, 17-37. doi: 10.1146/annurevphyto-082712-102239

Wang, D., Yu, J. M., Dorosky, R. J., Pierson, L. S. III, and Pierson, E. A. (2016). The phenazine 2-hydroxy-phenazine-1-carboxylic acid promotes extracellular dna release and has broad transcriptomic consequences in Pseudomonas chlororaphis 30-84. PLoS One 11:e0148003. doi: 10.1371/journal.pone.01 48003

Wang, D. P., Lee, S. H., Seeve, C., Yu, J. M., Pierson, L. S., and Pierson, E. A. (2013). Roles of the Gac-Rsm pathway in the regulation of phenazine biosynthesis in Pseudomonas chlororaphis 30-84. MicrobiologyOpen 2, 505-524. doi: 10.1002/ mbo3.90
Wang, D. P., Yu, J. M., Pierson, L. S., and Pierson, E. A. (2012). Differential regulation of phenazine biosynthesis by RpeA and RpeB in Pseudomonas chlororaphis 30-84. Microbiology 158, 1745-1757. doi: 10.1099/mic.0.059352-0

Wang, N., Lu, S.-E., Records, A. R., and Gross, D. C. (2006). Characterization of the transcriptional activators SalA and SyrF, which are required for syringomycin and syringopeptin production by Pseudomonas syringae pv. syringae. J. Bacteriol. 188, 3290-3298. doi: 10.1128/jb.188.9.3290-3298.2006

Wang, Y., Kern, S. E., and Newman, D. K. (2010). Endogenous phenazine antibiotics promote anaerobic survival of Pseudomonas aeruginosa via extracellular electron transfer. J. Bacteriol. 192, 365-369. doi: 10.1128/jb. 01188-09

Wang, Y., Wilks, J. C., Danhorn, T., Ramos, I., Croal, L., and Newman, D. K. (2011). Phenazine-1-carboxylic acid promotes bacterial biofilm development via ferrous iron acquisition. J. Bacteriol. 193, 3606-3617. doi: 10.1128/jb.00396-11

Waters, C. M., and Bassler, B. L. (2005). Quorum Sensing: cell-to-cell communication in bacteria. Annu. Rev. Cell Dev. Biol. 21, 319-346. doi: 10. 1146/annurev.cellbio.21.012704.131001

Whistler, C. A., and Pierson, L. S. III (2003). Repression of phenazine antibiotic production in Pseudomonas aureofaciens strain 30-84 by RpeA. J. Bacteriol. 185, 3718-3725. doi: 10.1128/jb.185.13.3718-3725.2003

Wood, D. W., Gong, F., Daykin, M. M., Williams, P., and Pierson, L. S. (1997). $\mathrm{N}$-acyl-homoserine lactone-mediated regulation of phenazine gene expression by Pseudomonas aureofaciens 30-84 in the wheat rhizosphere. J. Bacteriol. 179, 7663-7670. doi: 10.1128/jb.179.24.7663-7670.1997

Wood, D. W., and Pierson, L. S. (1996). The phzI gene of Pseudomonas aureofaciens 30-84 is responsible for the production of a diffusible signal required for phenazine antibiotic production. Gene 168, 49-53. doi: 10.1016/0378-1119(95) 00754-7

Xu, H. Y., Zhao, Y. C., Qian, G. L., and Liu, F. Q. (2015). XocR, a LuxR solo required for virulence in Xanthomonas oryzae pv. oryzicola. Front. Cell. Infect. Microbiol. 5:37. doi: 10.3389/fcimb.2015.00037

Yu, J. M., Wang, D. P., Pierson, L. S., and Pierson, E. A. (2017). Disruption of MiaA provides insights into the regulation of phenazine biosynthesis under suboptimal growth conditions in Pseudomonas chlororaphis 30-84. Microbiology (Reading) 163, 94-108. doi: 10.1099/mic.0.000409

Yu, J. M., Wang, D. P., Ries, T. R., Pierson, L. S., and Pierson, E. A. (2018). An upstream sequence modulates phenazine production at the level of transcription and translation in the biological control strain Pseudomonas chlororaphis 30-84. PLoS One 13:e0193063. doi: 10.1371/journal.pone.0193063

Zhang, L. L., Jia, Y. T., Wang, L., and Fang, R. X. (2007). A proline iminopeptidase gene upregulated in planta by a LuxR homologue is essential for pathogenicity of Xanthomonas campestris pv. campestris. Mol. Microbiol. 65, 121-136. doi: 10.1111/j.1365-2958.2007.05775.x

Zhang, Z. G., and Pierson, L. S. (2001). A second quorum-sensing system regulates cell surface properties but not phenazine antibiotic production in Pseudomonas aureofaciens. Appl. Environ. Microbiol. 67, 4305-4315. doi: 10.1128/aem.67.9. 4305-4315.2001

Conflict of Interest: The authors declare that the research was conducted in the absence of any commercial or financial relationships that could be construed as a potential conflict of interest.

Copyright (C) 2020 Pan, Pierson and Pierson. This is an open-access article distributed under the terms of the Creative Commons Attribution License (CC BY). The use, distribution or reproduction in other forums is permitted, provided the original author(s) and the copyright owner(s) are credited and that the original publication in this journal is cited, in accordance with accepted academic practice. No use, distribution or reproduction is permitted which does not comply with these terms. 